\title{
O debate metodológico nos estudos de congruência política: uma revisão da literatura internacional
}

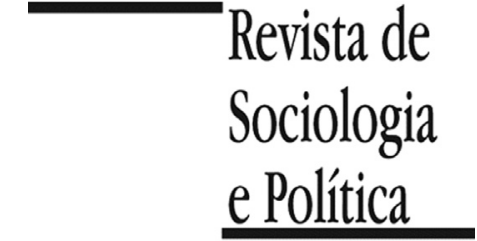

DOI 10.1590/1678-987319276902

\begin{abstract}
Yan de Souza Carreirão' (10
RESUMO Introdução: O ensaio bibliográfico analisa a literatura internacional dedicada a investigar empiricamente o grau de congruência entre as preferências políticas dos eleitores e de seus representantes. O trabalho faz uma revisão dos principais tópicos do debate metodológico presente nesta literatura. Materiais e Métodos: Foram resenhados os artigos mais influentes neste debate, ou seja, os mais citados e/ou cujas propostas metodológicas tenham sido mais utilizadas em estudos posteriores. A ênfase é na comparação das vantagens e desvantagens atribuídas ao uso de diferentes fontes e tipos de informação para estimar aquelas preferências e ao uso de diversos indicadores para calcular o grau de congruência entre as preferências dos atores envolvidos na relação de representação. Resultados: Ao final é feito um balanço, apontando as estratégias metodológicas julgadas mais promissoras para este tipo de análise. Discussão: Espera-se que esta revisão possa incentivar o desenvolvimento desse tipo de estudos, ainda muito incipientes no Brasil e representar, para os pesquisadores interessados, um atalho para a compreensão dos aspectos metodológicos aí envolvidos.
\end{abstract}

PALAVRAS-CHAVE: representação política; congruência política; opinião pública; preferências políticas dos representantes; metodologia.

Recebido em 29 de Agosto de 2017. Aceito em 3 de Maio de 2018. Revisado pelo autor em 28 de Maio de 2018.

\section{Introdução ${ }^{1}$}

\author{
${ }^{1}$ Este artigo é fruto de \\ pesquisa apoiada pelo $\mathrm{CNPq}$, \\ por meio de Bolsa de \\ Produtividade. Agradeço \\ aos/às pareceristas \\ anônimos/as da Revista de \\ Sociologia e Política pelas \\ sugestões.
}

\footnotetext{
${ }^{2}$ As relações entre "representação" e "responsividade" são discutidas em Przeworski,
}

$\mathrm{U}$ ma significativa literatura sobre representação política foi produzida nos últimos 50 anos - especialmente nos Estados Unidos e na Europa a partir da análise empírica da "congruência política" entre as preferências políticas dos cidadãos e seus representantes, ou da congruência entre as políticas aprovadas pelos legisladores (ou implementadas pelo Executivo) e as preferências dos cidadãos.

Este tipo de análise certamente não esgota o estudo sobre representação política. Para compreender de forma mais abrangente o processo de representação, são necessários, também, estudos preocupados com a "representação descritiva" (grau de semelhança entre representantes e representados em certos atributos como origem profissional, gênero, etnia etc.) e análises da qualidade da representação baseadas em outros critérios que não a congruência entre eleitores e representantes, como justiça, respeito a direitos de minorias etc. Porém, os estudos de congruência são uma parte importante na compreensão do processo de representação política, já que a ideia central que os norteia e justifica é a de que, na democracia representativa, espera-se que os representantes sejam "responsivos" às preferências, opiniões ou interesses dos cidadãos.

Esta ideia está presente, para mencionar apenas dois autores fundamentais, em Dahl (1997, p.1): "uma característica essencial da democracia é a contínua responsividade do governo às preferências dos cidadãos", e em Pitkin (1967, p.209): "representar significa agir no interesse dos representados, de uma maneira responsiva a eles" $"$.

Em trabalho anterior com a finalidade de estimular o debate sobre essa literatura no país, ainda pouco presente em nossa produção acadêmica ${ }^{3}$ 
Stokes e Manin (1999) e Miguel (2014), entre outros. Todas as traduções de citações são de responsabilidade do autor do artigo.

${ }^{3}$ Exceções importantes são Ames, Pereira e Rennó (2011), Pederiva e Rennó (2015) e Boas e Smith (2016)
(Carreirão 2015), apresentei brevemente a evolução histórica desses estudos, situando diferenças metodológicas centrais relacionadas às unidades de análise (comparação entre eleitores, de um lado, e representantes individuais, partidos, o Congresso como um todo ou governos, de outro) e ao escopo espaço-temporal - estudos num único país ou estado vs. estudos comparados - e estudos "estáticos" vs. "dinâmicos". Propus ali, também, uma agenda de pesquisa sobre congruência política no país e indiquei alguns dos problemas a serem superados no caso brasileiro.

O presente artigo explora de forma mais detalhada aspectos específicos do debate metodológico no tipo de estudos centrados em comparar as preferências dos eleitores com as preferências dos representantes ("mass-elite congruence studies").

No estudo de representação política, mais importante do que comparar preferências de cidadãos e representantes é comparar as preferências dos eleitores com as políticas públicas aprovadas pelos representantes. Mas, como Dalton (2008, p.220) ressalta, "o acordo entre elites e cidadãos é um padrão básico para julgar a representatividade de um sistema democrático. O acordo é um teste significativo porque determina se os tomadores de decisão abordarão o processo decisório a partir das mesmas preferências do público e, como tal, é um objetivo central da democracia representativa". Nessa mesma linha, as conclusões do influente estudo de Powell (2000) sobre 20 democracias ocidentais (comparando o posicionamento ideológico do cidadão mediano com o de governos) ressaltam também a importância desse tipo de estudo para a avaliação de um aspecto central do processo de representação política: "é encorajador para a democracia que nós não vejamos governos extremistas governando eleitorados centristas e vice-versa. E que não achemos governos muito conservadores governando eleitorados de esquerda [...]. Há, aqui, então, uma mensagem positiva sobre a democracia" (Powell 2000, p.243). Por fim, Holmberg (2011, pp.56-57) também justifica o tipo de pesquisa aqui analisado, afirmando que é importante estudar a relação entre as opiniões das massas e das elites para verificar se, ao longo do tempo, são as preferências dos representantes que se aproximam das dos cidadãos (representation from below) ou vice-versa (representation from above).

Para atingir o objetivo central destes estudos é necessário estimar as preferências políticas dos cidadãos e de seus representantes para, então, calcular a congruência. Para esse cálculo, é preciso partir de alguma forma de operacionalizar o conceito de congruência. O debate metodológico é centrado especialmente nas vantagens e desvantagens relativas ao uso de diferentes: 1) fontes de informação (surveys com eleitores e parlamentares, manifestos partidários, avaliação de posicionamento ideológico de partidos por especialistas etc.); (2) tipos de informação (posições em relação a temas específicos $v s$. medidas globalizantes, como posicionamento numa escala esquerda-direita, entre outras) a partir das quais se estimaria as preferências de cidadãos e representantes; (3) formas de cálculo dos indicadores de congruência entre cidadãos e representantes (uso de correlações, de tendências médias ou de diferenças nas distribuições completas das preferências de eleitores e representantes). As formas concretas como os estudos empíricos operacionalizam a análise da congruência envolvem escolhas sobre estes três aspectos simultaneamente. Apenas com finalidade analítica, serão apresentadas para cada um deles as principais opções presentes na literatura. No debate sobre as vantagens e desvantagens de cada forma de operacionalização, porém, é mais difícil separar os três aspectos, dado que algumas das escolhas dos indicadores de congruência estão vinculadas às escolhas feitas em relação às fontes e tipos de informação utilizados para estimar as preferências dos atores. 
A próxima seção descreve as principais opções de fontes e tipos de informação utilizados para estimar as preferências de cidadãos e representantes. $\mathrm{Na}$ seção III, apresenta-se os principais argumentos esgrimidos no debate sobre estes tópicos. Na seção IV, apresenta-se e se discute alguns dos principais tipos de indicadores utilizados para mensurar a congruência entre estas preferências. Ao final, faz-se um balanço dos argumentos apresentados ao longo do artigo.

\section{Fontes e tipos de informação para estimar as preferências de eleitores e representantes}

As estimativas das preferências de cidadãos (ou eleitores) usualmente são baseadas em respostas dos próprios eleitores a perguntas de surveys, seja analisando suas posições em relação a temas específicos (estudos de issue congruence), seja usando algum indicador "globalizante" de suas posições políticas (estudos de ideological congruence), em geral uma escala Esquerda-Direita. Outros tipos de medidas "globais" das preferências dos eleitores, diferentemente do posicionamento numa escala E-D, são formadas por índices que agregam as posições dos eleitores em relação a um conjunto de temas específicos. Uma das formas mais influentes é o domestic policy mood, uma medida construída originalmente por Stimson (1991). Segundo Stimson, Mackuen e Erikson (1995, p.548), o policy mood é uma dimensão subjacente às preferências expressas pelos eleitores em relação a alternativas de políticas públicas e pode ser interpretado como esquerda vs. direita, ou, mais especificamente, como preferências globais por um governo federal maior, mais ativo, em oposição a um menor, mais passivo, em relação ao conjunto de políticas públicas "domésticas" (excluindo-se a política externa).

O policy mood vem sendo utilizado como indicador do "humor" do público (no sentido acima) por vários estudos de opinião pública e de congruência política. Foi utilizado por seu criador e colaboradores (Stimson, Mackuen \& Erikson 1995; Erikson, Mackuen \& Stimson 2002) para comparar, ano a ano, a variação do "humor" do público norte-americano com o conjunto das decisões tomadas por certas instituições (presidência, House of Representatives, Senado e Suprema Corte), de forma a ver se estas decisões são responsivas àquele "humor". Isso corresponde a um tipo de estudo de congruência que compara as preferências dos eleitores com as políticas públicas aprovadas ou implementadas pelo sistema político. É possível, porém, usar uma medida como o policy mood também para medir o conjunto das preferências dos representantes (deputados ou senadores), a partir de surveys, de forma a verificar se a variação do "humor" dos representantes (em relação à maior ou menor intervenção do Estado nas políticas públicas) acompanha a variação do "humor" do eleitorado. Outros tipos de índices também podem ser utilizados com proveito nesta perspectiva. Um exemplo pode ser visto em Belchior e Freire (2012) e Freire e Belchior (2013), que a partir de duas baterias de questões, aplicadas tanto a eleitores como a representantes, criaram dois índices, relativos à dimensão "esquerda/direita econômica" (Economic left-right) e à dimensão "autoritarismo-libertarismo" (Libertarian-authoritarian divide), comparando cidadãos e representantes diretamente a partir destes índices e não das respostas a cada $i s$ sue individualmente.

Por fim, em muitos estudos as preferências de eleitores não são tomadas diretamente a partir de suas respostas a questões de surveys, mas são "reveladas" por sua preferência partidária ou pelo voto.

Quanto às preferências dos representantes, as principais formas de medir essas preferências são: 1) a partir do conteúdo dos manifestos dos partidos a que pertencem; (2) a partir de surveys com experts, para estimar as posições políticas dos partidos; (3) a partir das percepções dos eleitores a respeito da 
posição dos partidos ${ }^{4}$; (4) perguntando-se diretamente aos parlamentares, em um survey, suas posições numa escala esquerda-direita ou em relação a questões (issues) específicas.

\section{Vantagens e desvantagens no uso das diversas fontes e tipos de informação}

Inicio pelo debate sobre as vantagens e desvantagens do uso de posições (de cidadãos e representantes) sobre temas específicos ou de seu posicionamento numa escala esquerda-direita (E-D).

\section{III.1. O uso da escala esquerda-direita}

${ }^{4}$ Os cidadãos posicionam-se e a cada partido político numa escala E-D. As posições dos legisladores e governos são estimadas a partir das posições dos partidos (Powell 2009, p.1479).

\footnotetext{
${ }^{5}$ Huber e Powell (1994, pp.293-295) destacam os problemas teóricos (apresentados por Arrow 1951; Aldrich \& McKelvey 1977; Riker 1982) inerentes à agregação de preferências individuais - e a consequente inadequação do uso da posição do eleitor mediano - quando há mais de uma dimensão envolvida.

${ }^{6}$ Estes autores, assim como Powell (2000, p.163), postulam que quando a distância ideológica (na escala E-D) entre partidos e eleitores é pequena, isso é um sinal positivo em relação à qualidade da representação (Rorschneider \& Whitefield 2012, p.87).
}

Otero-Felipe e Rodríguez-Zepeda (2010) sintetizam alguns dos argumentos a favor de pensar a política em termos de esquerda e direita:

"[...] com base na abordagem de Downs (1957), assume-se que as preferências políticas podem ser ordenadas espacialmente, da esquerda para a direita e que esta é uma dimensão na qual os partidos políticos competem, mas também através da qual eles podem se comunicar mais clara e efetivamente com seus potenciais eleitores. Dessa forma [...] a divisão esquerda/direita reduz o conflito político a uma única dimensão, ao menos em boa parte das democracias avançadas. Da mesma forma, o eleitor irá usar a ideologia de modo a evitar custos de informação, usando-a como um atalho informacional a fim de se posicionar sobre os diferentes temas e escolher em quem votar" (Otero-Felipe \& Rodríguez-Zepeda 2010, p.5).

Mais especificamente, alguns dos principais argumentos a favor do uso da escala esquerda-direita como estimativa das posições políticas de cidadãos e representantes são: 1) usar diversos issues ou dimensões políticas implica incorrer no problema discutido pela teoria da escolha social, de agregação de preferências quando há múltiplas dimensões ${ }^{5}$. O uso de uma única dimensão (como no caso da escala esquerda-direita, que teoricamente sintetizaria as demais, ou do domestic public mood) permitiria eliminar esse problema; (2) a localização na escala seria baseada "em importantes considerações em um dado sistema partidário, independentemente do conteúdo específico da ideologia E-D” (Rohrschneider \& Whitefield 2012, p.86) ${ }^{6}$; (3) a escala E-D oferece uma métrica comum que permite comparações entre diversos países e entre eleitores e partidos (Powell 2000; Dalton 2008).

De outro lado, segundo os críticos, o uso dessa escala seria inadequado nas seguintes circunstâncias: 1) se a escala E-D não tiver significado para parte considerável dos eleitores; (2) se o posicionamento dos partidos não reflete as mesmas posições políticas (frente a issues) que eleitores usam para posicionar a si mesmos; (3) se as preferências dos eleitores em muitos issues não forem adequadamente agregadas na escala (Powell 2000; Andeweg 2011).

Quanto ao primeiro desses temas, cabe dizer que não há consenso. Powell (2000, p.162) postula que na maioria dos países por ele estudados (20 democracias mais consolidadas) "a linguagem da esquerda e direita reflete (e talvez ajude a criar) um discurso unidimensional familiar aos cidadãos e às elites [...]. Estudos de públicos de massa e de elites políticas em muitos de nossos países mostram que eles são capazes de pensar sobre temas de políticas públicas na linguagem de esquerda e direita". Em artigo posterior, porém, o mesmo autor afirma, no mínimo matizando aquela postulação, que em alguns estudos "assume-se que o cidadão tem um autêntico posicionamento na escala E-D, embora cidadãos menos envolvidos podem posicionar-se na escala adivinhando [by guessing] - até mesmo influenciados pelo partido que apoiam" (Powell 2009, p.1479). Mais recentemente, Freire e Kivistik (2013), analisando dados do Comparative National Election Project relativos a 14 países em 5 continen- 
${ }^{7}$ Além dos já mencionados, vários estudos recentes têm ampliado o conhecimento sobre congruência ideológica na América Latina: Bornschier (2013); Otero-Felipe e Rodríguez-Zepeda (2014); Saiegh (2015); Selios (2015); Lupu, Selios \& Warner (2017), entre outros. tes, concluíram que a divisão E-D é largamente reconhecida, embora em menor grau em países fora da Europa e da América do Norte. É mais presente (tanto no autoposicionamento dos eleitores quanto na localização, pelos eleitores, dos partidos) em democracias mais longevas e em países com meios de comunicação livres do que em novas democracias e países sem sistemas livres de mídia. No caso da localização dos partidos, o tamanho influencia: partidos maiores são mais facilmente localizados pelos eleitores. As variáveis individuais mais influentes são as "suspeitas" usuais: idade, educação, interesse político, força da identificação partidária e grau de exposição à mídia.

Em relação à América Latina, Otero-Felipe e Rodríguez-Zepeda (2010, p.6) afirmam que "a relevância da dimensão ideológica tem sido objeto de debate na América Latina. Tem se argumentado que a política na região é predominantemente personalista, clientelista e populista, de forma que elementos ideológicos e programáticos estariam praticamente ausentes. Não obstante, esta generalização foi subsequentemente refutada". Os autores concordam com Colomer e Escatel (2005), que aponta que a dimensão E-D é relativamente útil para uma grande parte dos eleitores da região. Na realidade, a situação parece ser bastante variável entre os eleitores da região. Analisando dados do Barômetro das Américas de 2010, Zechmeister e Corral (2013) mostram que tanto variáveis de nível individual (educação, interesse politico e sofisticação política), quanto variáveis contextuais (grau de polarização política, fragmentação partidária e volatilidade eleitoral) afetam a compreensão dos eleitores latinoamericanos quanto aos rótulos "esquerda" e "direita". Ou seja, a capacidade de os eleitores utilizarem estes rótulos para compreender a política e se vincular a partidos varia muito entre eleitores e em diferentes contextos ${ }^{7}$.

No caso do Brasil, porém, esse parece ser um sério problema: embora Singer (2000) aponte em direção contrária, vários estudos mostram que para boa parte dos eleitores (especialmente os de baixo nível de escolaridade) a escala esquerda-direita não tem um significado claro (Almeida 2001a; 2001b; Carreirão 2002; Zucco 2011; Rennó et al., 2011; Oliveira \& Turgeon 2015).

Sobre o item 3, mencionado acima, há também divergências importantes: Dalton et al. (2011, p.85) afirmam que o enquadramento E-D não se limita, hoje, às tradicionais questões socioeconômicas ou mesmo religiosas. Um conjunto de novos issues (direitos de imigrantes, limites para a participação em missões da ONU e impostos ambientais) que entraram na agenda foram integrados àquele enquadramento. Já Thomassen (2012), num excelente balanço da literatura que utiliza a dimensão esquerda-direita, aponta, de um lado, (1) que os estudos empíricos mostram que essa dimensão é de fato a principal dimensão para enquadrar a disputa partidária na Europa; (2) que os eleitores, nesses países, conseguem localizar a si próprios e os partidos na escala; (3) que os partidos mantêm políticas de acordo com sua posição ideológica, quando no governo. Como consequência, a dimensão E-D parece ser um instrumento efetivo para a representação política, conectando as preferências políticas do público às posições dos partidos no parlamento e às políticas públicas (Thomassen 2012, p.14). Por outro lado, a pesquisa mostra que as posições políticas dos eleitores em várias dimensões políticas relevantes (especialmente "lei e ordem", imigração, o lugar de minorias étnicas na sociedade e a integração europeia) não podem ser previstas por sua posição E-D, ou seja, a escala não abarca aquelas dimensões. Daí decorre o seguinte problema:

\footnotetext{
"Se partidos políticos competem na dimensão E-D e os eleitores votam em acordo com suas posições nessa dimensão, porque é a dimensão mais saliente para eles, eles talvez possam votar no partido "errado" em relação a temas que não são alinhados à dimensão E-D e assim serem pobremente representados em relação a esses temas" (Thomassen 2012, pp.14-15).
} 
III.2. As principais abordagens

${ }^{8}$ As posições medianas dos legisladores e do governo são estimadas a partir desses posicionamentos dos partidos. No caso de coalizões, usualmente se assume que a posição do governo é uma média ponderada (segundo o peso de cada partido no governo, em números de ministérios ou de cadeiras na câmara baixa) dos partidos que formam a coalizão
Cabe mencionar que autores como Andeweg (2011) e Holmberg (2011), entre outros, têm realizado análises de congruência com base nas opiniões de cidadãos e representantes em relação a temas específicos. Trata-se de um tipo de análise bastante interessante que, além de analisar o grau em que ocorre uma congruência ideológica mais "global" entre eleitores e representantes, permite verificar exatamente em relação a quais temas há maior ou menor concordância. Porém, o problema formulado pela teoria da escolha social, da agregação das preferências individuais em um espaço político multidimensional (ver nota 5), não parece ser enfrentado nestes estudos.

Várias combinações são possíveis a partir das fontes e tipos de informação utilizados para estimar as preferências de um ou outro agente da relação de representação. Nem todas as combinações, porém, são adequadas ou igualmente consideradas na literatura. Em um importante estudo, em que faz um balanço dos dados e métodos usados nos estudos de congruência política desse tipo, Powell (2009) indica o que considera as três principais abordagens para medir congruência, considerando os diferentes métodos de estimação das preferências de cidadãos (ou eleitores) e representantes:

1) a abordagem "posição do cidadão medida por survey/posição do representante medida por survey com experts";

2) a abordagem "voto partidário/manifesto partidário";

3) a abordagem "identificação do cidadão/percepção do cidadão".

Partindo dessa sumarização, acrescento outras variantes de análise, bem como comentários de outros autores.

Em primeiro lugar, o citizen survey/expert survey approach - utilizado especialmente em estudos comparando o grau de congruência alcançado em diferentes países - em geral mede as preferências políticas dos eleitores a partir de surveys que lhes pedem para se posicionarem numa escala esquerda-direita (E-D). A posição dos representantes é estimada a partir de surveys com experts de cada país, em que se pede que eles localizem cada partido na escala E-D. Assume-se que todos os representantes tenham a mesma posição de seus partidos. A congruência, na maioria dos estudos é medida pela distância entre as posições do cidadão mediano e do legislador mediano (ou do governo) ${ }^{8}$; mas há outras formas possíveis de calculá-la, como será visto adiante. Powell (2009) afirma que a força desta abordagem é que se pode esperar que os especialistas em cada país saibam as "verdadeiras" posições dos partidos, especialmente se os surveys envolverem um grande número de especialistas. Além disso, é um método relativamente barato e que possibilita obter dados que de outra forma seriam difíceis de se obter.

Quanto às desvantagens, um dos problemas é que a pressuposição (operacional) de que todos os representantes têm a mesma posição de seus partidos ignora as variações ideológicas entre legisladores de um mesmo partido (Andeweg 2011). Outro problema é que não se pode saber se especialistas e cidadãos têm as mesmas coisas em mente quando localizam os partidos (e a si próprios) na escala; segundo Golder e Stramski (2010, p.98), os dados do Comparative Studies of Electoral Systems (CSES) - dos mais utilizados em comparações dos graus de congruência entre países - fornecem indícios consideráveis de que há um significativo problema de differential item functioning (DIF): comparando-se os posicionamentos dos partidos a partir das respostas dos cidadãos aos surveys do CSES com a localização feita por peritos, em $90 \%$ dos casos há diferenças estatisticamente significativas (1 ponto na escala em $25 \%$ 
${ }^{9} \mathrm{Na}$ realidade, este problema pode ocorrer em outras "abordagens", se houver uma defasagem temporal significativa entre os momentos em que são aplicados os instrumentos para estimar as preferências dos cidadãos (survey ou voto numa eleição) e as dos representantes (survey com os próprios representantes ou manifestos partidários).

${ }^{10}$ Os dados estão disponíveis em Manifesto Project (2017). Em 19 de julho de 2017, o banco contava com dados de 4.174 manifestos, de 1.085 partidos em 713 eleições, num conjunto de 60 países.

Referências importantes nessa produção são McDonald, Mendes e Budge (2004); Budge et al. $(2001 ; 2012) \mathrm{e}$ Klingemann et al. (2006). No Brasil, Tarouco (2011), Tarouco e Madeira (2013) e Madeira e Tarouco (2011).

${ }^{11}$ Na maioria desses estudos, a posição do eleitor mediano se baseia na distribuição dos votos partidários e na premissa de que cada eleitor votou no partido ideologicamente mais próximo (Powell 2009, p.1478). A congruência é calculada da mesma forma que na abordagem anterior, pela distância entre as posições do cidadão mediano e do legislador mediano (ou do governo).

12 Além dos argumentos aqui considerados, para uma defesa do uso de posições políticas de partidos e eleitores a partir de manifestos partidários - e para uma discussão dos aspectos metodológicos aí envolvidos ver especialmente Budge et al. (2001) e Klingemann et al. (2006). dos casos e 1,5 em 12\%). Powell (2009) destaca, além disso, que o estudo de McDonald, Mendes e Budge (2004) mostra que, devido ao fato de não haver muitos surveys com especialistas, esses estudos assumem que as posições políticas são estáveis durante um período de cinco anos, pressuposto que pode ocasionalmente levar a erro 9 . Por fim, um risco apontado por Andeweg (2011) é o de que os experts locais podem usar seu conhecimento das preferências ideológicas dos eleitores com preferência por um partido como um dos ingredientes para estimar a posição do partido, enviesando os resultados na direção de alta congruência.

Em segundo lugar, o party vote/party manifesto approach é comumente utilizado nos trabalhos ligados ao Manifesto Group Research (MGR)/Comparative Manifestos Program (CMP), programa de pesquisa que reúne hoje uma base de dados importantíssima sobre as posições de partidos políticos (expressas em seus manifestos) em relação a um grande número de issues ${ }^{10}$. Em geral, a posição E-D dos partidos é estimada a partir de suas posições em relação a vários issues. As posições dos partidos são estimadas subtraindo-se a porcentagem de enunciados num manifesto em que os partidos são considerados "de esquerda" à porcentagem de enunciados tidos como "de direita". As posições dos eleitores são estimadas a partir das posições dos partidos em que votaram ${ }^{11}$.

Segundo Powell, uma das vantagens dessa abordagem é que os manifestos são promessas feitas pelos partidos durante as campanhas eleitorais e têm certa autenticidade como medidas específicas, para aquele momento, das posições partidárias (em contraste com o pressuposto de posições constantes ao longo do tempo que em geral resultam da aplicação de surveys a especialistas). Do lado dos eleitores, usar o voto teria a vantagem de considerar uma manifestação de comportamento que poderia ser vista como mais autêntica e válida do que uma resposta a uma questão abstrata de um survey. Isso contraria argumento do próprio autor em trabalho anterior (Powell 2000) e o de Budge et al. (2012), de que usar diretamente as preferências políticas de eleitores e representantes é melhor do que usar os votos dos eleitores como expressão de suas preferências políticas, porque as primeiras são manifestações de preferências (por políticas) não constrangidas pelas ofertas partidárias, enquanto as preferências reveladas pelo voto sofrem esse constrangimento. Outra vantagem seria a de que essa abordagem estima as posições do eleitor e do representante medianos na mesma escala, desenhada para permitir comparações entre países e ao longo do tempo. Como se têm dados para muitos países em muitas eleições, em alguns casos desde meados da década de 1940, permite-se uma análise temporal que outros métodos não permitem ${ }^{12}$.

Mas há também sérios problemas em potencial: inicialmente, como a ênfase dos estudos de manifestos é na frequência (porcentagem) de enunciados esquerda-direita, eles captariam mais a saliência de temas esquerda-direita para um partido do que a posição E-D do partido (Golder \& Stramski 2010; Andeweg 2011). Segundo Golder e Stramski (2010, p.99) outra limitação seria que os itens constitutivos da medida do CMP (os temas que definem se as posições de um partido são de esquerda ou de direita) são os mesmos para todos os países e períodos, o que impediria os pesquisadores de captarem diferenças contextuais ou temporais no significado da dimensão E-D. Isso seria potencialmente problemático na comparação de muitos países num período muito longo (um tipo de estudo muito interessante e que teria melhores resultados se comparasse diretamente respostas de cidadãos e de representantes a questões de survey). Outro problema deriva da pressuposição de que todos os eleitores de um partido compartilham sua posição ideológica, o que não necessariamente é verdade: o voto pode ser dado para punir outro partido que tenha feito um mau governo, pode ser motivado pelas características pessoais de candidatos etc. A atribuição de preferência ideológica por um partido a uma proporção de eleitores que vota 
${ }^{13}$ Uma opção mais interessante seria comparar as posições dos eleitores sobre determinados temas com as posições dos partidos sobre estes mesmos temas, a partir de seus manifestos. Algumas das desvantagens seriam eliminadas. Este tipo de análise permitiria verificar se os partidos têm posições semelhantes às de seus "adeptos" (definidos em termos de identificação partidária ou de voto).

14 Para uma perspectiva mais crítica em relação ao uso da técnica de Wordscore para estimar posições políticas, ver Lowe (2008). em bases não ideológicas pode levar a superestimar o grau de congruência, principal problema apontado por Andeweg (2011) em relação a esse tipo de procedimento ${ }^{13}$.

Mais recentemente, foram desenvolvidas metodologias alternativas à do Comparative Manifestos Program na estimação das posições políticas dos partidos, utilizando-se técnicas automatizadas de análise de conteúdo de textos (os manifestos partidários, nesse caso): as técnicas de Wordscore (Laver, Benoit \& Garry 2003) e Wordfish (Slapin \& Proksch 2008). No lugar da codificação "manual" (por especialistas) de trechos dos manifestos, a técnica de Wordscore, segundo seus criadores, trata

"textos não como discursos para serem lidos, compreendidos e interpretados por significado [...] mas como coleções de dados de palavras contendo informações sobre a posição dos autores dos textos sobre as dimensões políticas predefinidas. Dado um conjunto de textos sobre os quais algo é conhecido, nossa técnica extrai dados a partir deles na forma de frequências de palavras e usa essas informações para estimar as posições políticas de textos sobre os quais nada é conhecido (Laver, Benoit \& Garry 2003, p.312).

Assim, para cada dimensão política a ser analisada, é criado um escore de frequência relativa para cada palavra que aparece nos textos (manifestos) de referência. Esse escore vai servir para estimar as posições de partidos em relação àquela dimensão política em outros manifestos. A técnica de Wordfish, por sua vez, não usa textos de referência, ou seja, não é "supervisionado", não requer informação prévia para produzir estimativas: a única entrada exigida pelo Wordfish é uma matriz que lista a frequência de cada palavra em todos os documentos. A principal vantagem atribuída a essa técnica é a redução drástica dos custos de conduzir a análise de conteúdo, "o que por sua vez aumenta muito o universo de textos e o número de atores para os quais as posições podem ser estimadas" (Hjorth et al., 2015). O principal questionamento, nesse tipo de uso da técnica, trata da validade das medidas calculadas como indicadores efetivos do posicionamento ideológico dos partidos, tópico sobre o qual há controvérsia na literatura. Klemmensen, Hobolt e Hansen (2007) estimaram o posicionamento ideológico de partidos dinamarqueses, usando Wordscores, a partir de manifestos partidários lançados entre 1945 a 2005. Compararam com as posições destes mesmos partidos medidas a partir da metodologia do CMP e ainda com surveys aplicados a especialistas, concluindo que a técnica de Wordscore chega a estimativas semelhantes às produzidas por estes outros métodos. Hjorth et al. (2015) estimaram as posições de 254 manifestos em 33 eleições na Alemanha e na Dinamarca usando as técnicas de Worscore e Worsfish. Concluíram que a técnica de Wordscores reproduz aproximadamente o mesmo posicionamento dos partidos obtido pelo CMP, por surveys com eleitores (que posicionavam os partidos numa escala ideológica) e por avaliações de especialistas, tanto para a Alemanha quanto para a Dinamarca, enquanto a técnica de Wordfish, só para a Alemanha ${ }^{14}$.

Em terceiro, o citizen identification/citizen perception approach baseia-se em surveys que solicitam aos cidadãos que localizem a si próprios e cada partido numa escala E-D. As posições de legisladores e governo são estimadas com base na percepção dos eleitores sobre o posicionamento dos partidos (e não a partir do posicionamento dos partidos segundo experts ou segundo seus manifestos). A congruência geralmente é calculada como a distância entre o posicionamento do cidadão e do representante medianos (embora essa não seja a única forma possível). Segundo Powell, a força desse método é permitir que cada cidadão interprete, de sua própria forma, o conteúdo de direita e esquerda, localizando a si e cada partido na escala. Assim, não seria necessário que as posições na escala sejam as mesmas entre diferentes cidadãos, períodos e países, sendo necessário apenas que a métrica seja similar. Uma desvantagem é que 
o método pressupõe que os cidadãos sejam realmente informados sobre a "real" posição de cada partido, o que pode não ser verdade para uma proporção significativa. Andeweg (2011) afirma que estimar a posição dos representantes (ou, mais precisamente, de seus partidos) a partir das percepções dos eleitores a respeito daquela posição enviesaria ainda mais os resultados em direção à congruência, já que os eleitores podem "achar" que suas posições são semelhantes às dos partidos com o qual se identificam (mecanismo de "projeção": o eleitor "projeta" suas próprias posições no partido com o qual se identifica).

Um procedimento que pode ser visto como intermediário entre a abordagem do citizen survey/expert survey approach e a abordagem do citizen identification/citizen perception approach é o adotado por Golder e Stramski (2010), que recorre, para estimar as posições E-D dos partidos, à localização média (nessa escala) de cada partido efetuada pelos $40 \%$ respondentes com mais escolaridade. Assim, apesar de se basear nas percepções dos eleitores, o procedimento apela também a um grupo com mais conhecimento político (que é a justificativa para o uso da primeira daquelas abordagens). Uma das justificativas para isso é que os eleitores menos escolarizados preferem situar um partido que não lhes é familiar no centro da escala (conforme análise de Alvarez e Franklin apud Golder e Stramski 2010, p.93), o que gera distorções na análise. E a principal vantagem seria situar cidadãos e representantes numa mesma métrica, já que os posicionamentos se baseiam apenas nas respostas de cidadãos. Pode-se questionar, no entanto, se a métrica utilizada pelos $40 \%$ mais escolarizados é a mesma dos demais $60 \%$. Em caso negativo, recairíamos no problema de comparar medidas a partir de métricas diferentes, argumento usado, como já vimos, pelos próprios autores contra a comparação entre posicionamentos E-D feitos por cidadãos e representantes.

\section{Os diferentes indicadores de congruência utilizados}

Outro tópico central no debate metodológico, associado à discussão sobre as abordagens metodológicas acima, refere-se aos indicadores utilizados para medir o grau de congruência. Isso envolve decisões sobre o nível de agregação dos dados tomados como base para calcular essas medidas e o tipo de estatística a ser usada. São apresentadas, a seguir, algumas das formulações mais influentes nesse debate.

Miller e Stokes (1963) utilizaram correlações ( $r$ de Pearson) entre as preferências de eleitores e representantes (de diferentes distritos) para calcular o grau de congruência. Os autores utilizaram questionários aplicados a amostras do público e dos membros do Congresso eleitos em um conjunto de distritos eleitorais nas eleições norte-americanas de 1958. Analisaram também os votos dados pelos parlamentares desses distritos na legislatura seguinte, o que lhes permitiu analisar as relações (por meio de correlações) entre quatro variáveis (num modelo conhecido como “diamante de Miller-Stokes”): 1) as opiniões dos cidadãos a respeito de uma série de issues; (2) as opiniões e (3) os votos dos seus representantes em cada distrito; (4) as percepções destes representantes sobre as opiniões de seus eleitores.

Achen (1977) faz uma crítica direta a Miller e Stokes e outros que, como eles, utilizaram algum tipo de medida de correlação bivariada para medir congruência. Começa por criticar a falta de reflexão sobre a teoria democrática a sustentar aquelas medidas: "correlações são virtualmente não interpretáveis no quadro da teoria democrática. As opiniões dos líderes podem se correlacionar com aquelas dos eleitores mesmo que os representantes estejam distantes dos eleitores e elas podem se correlacionar fracamente quando os representantes estão mais próximos" (Achen 1978, pp.475-476). Isso porque 
“correlações não podem ser comparadas entre amostras [...]; duas correlações podem diferir porque as variâncias nas amostras diferem e não porque a relação subjacente mudou. [...] Quando comparamos diferentes amostras, então um pequeno $\mathrm{R}^{2}$ não nos dá garantia de que a relação é fraca, nem um grande $\mathrm{R}^{2}$ garante que ela é forte" (Achen 1977, p.807).

E ainda: "por sua natureza, correlações destroem a comparabilidade entre amostras, o que significa que representantes de dois diferentes países não podem ser comparados nem podem ser comparadas duas diferentes dimensões políticas em um único país” (Achen 1977, pp.807-809).

Em artigo posterior, Achen (1978) propôs, no lugar de correlações, três indicadores do grau de congruência: proximidade, centrismo e responsividade - indicadores que refletiriam, segundo o autor, "os conceitos liberal-democráticos de igualdade entre os cidadãos, neutralidade em relação a alternativas e soberania popular" (Achen 1978, p.475). Ao tentar mensurar a "representatividade", a escolha de um ou outro indicador depende de quais os valores privilegiados pelo investigador ou qual sua pergunta de pesquisa.

Proximidade é uma medida de representatividade associada à distância ideológica entre eleitores e representantes, já que "um bom representante se assemelha a seus eleitores; por alguma medida ele é 'próximo' a eles” (Achen 1978, p.481).

Formalmente, Achen define assim essa medida:

"Em uma dimensão temática (issue dimension), a proximidade entre representante e eleitor no eleitorado $j, R_{j}$, é definida formalmente como a diferença quadrática média entre as posições na escala do representante e do eleitor. Com amostra aleatória simples, sua estimativa não enviesada é a diferença quadrática média na amostra, $R_{j}$.

$R_{j}=\frac{1}{n_{j}} \sum\left(c_{i j}-r_{j}\right)^{2}$,

onde $c_{i j}$ é a posição na escala de opinião do $i$-ésimo eleitor do $j$-ésimo eleitorado, $r_{j}$ é a posição do representante e $n_{j}$ é o tamanho da amostra do eleitorado. Quando estimativas como essas são formadas para cada conjunto de eleitorados, sua média é uma estimativa da distância média da jurisdição como um todo, denotada por R, a "proximidade". Quanto maior a proximidade, mais distante os eleitos estão dos eleitores ao longo da jurisdição; quanto mais distantes estão, menos representativos nesse sentido" (Achen 1978, pp.483-484).

Segundo Achen, este conceito de representatividade se relaciona com a norma da igualdade na teoria liberal da representação. Se a função do representante é reproduzir as opiniões dos cidadãos, então cada voz deve ser contada igualmente.

Segundo o próprio autor, o problema de uma medida como esta é que ela pode ser muito afetada pela distribuição de preferências dos eleitores. Conforme mostra a Figura 1, num hipotético distrito 1 em que as distâncias de posicionamento entre os eleitores sejam pequenas (amplitude total $=0,5$ ), mesmo que o representante ocupe a posição mais extrema, a medida de proximidade pode resultar pequena; de outro lado, no distrito 2, em que as preferências dos eleitores são mais extremas (amplitude total $=1,0$ ), mesmo o representante se colocando na posição média, a medida de proximidade pode ser maior do que no distrito 1. O representante do distrito 2 não pode fazer nada para melhorar sua distância em relação ao eleitor médio e, no entanto, por esta medida pareceria que seu desempenho é inferior ao representante do distrito 1 , que ocupa uma posição extrema no âmbito de seu distrito.

Uma medida proposta para sanar este problema e medir o desempenho dos representantes em termos de representatividade é o centrismo, que leva em 
Figura 1 - Três eleitorados, cada qual com três eleitores (C1, C2 e C3) e um representante (R), distribuídos ao longo de uma dimensão ideológica

\section{Distrito 1}

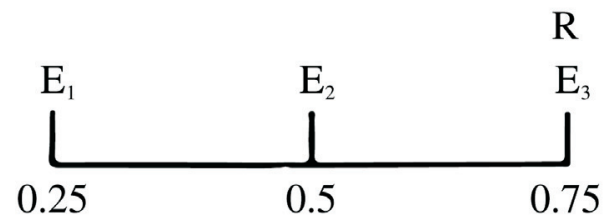

\section{Distrito 2}

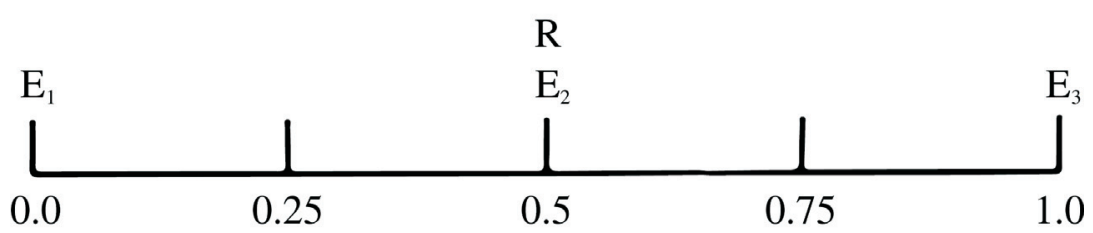

\section{Distrito 3}

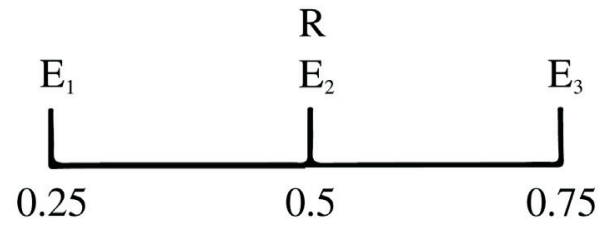

Fonte: O autor, a partir de Achen (1978).

Nota: As traduções mantiveram os títulos (e sub-títulos) de todas as figuras, como publicados nas fontes.

consideração a variância (interna a cada unidade de análise: distrito, estado ou país) das preferências dos eleitores: "a eficiência ou centralidade do representante pode ser medida pela diferença entre sua proximidade e a variância da opinião do eleitorado. Chamamos essa diferença de centrismo (centrism score)" (Achen 1978, p.487). A fórmula para calcular o centrismo, internamente a um distrito $j$ é:

$$
\hat{C} j=R_{j}-w_{j}^{2}
$$

onde $\hat{C} j$ é centrismo, $R_{j}$ é proximidade e $w_{j}^{2}$ é a variância das preferências dos

${ }^{15}$ A variância, por sua vez é calculada por meio da fórmula $w_{j}^{2}=\left(1 / n_{j}-1\right) \Sigma\left(c_{i j}-c_{j}\right)^{2}$, onde $n_{j}$ é o tamanho da amostra (eleitorado), $c_{i j}$ é a posição, na eleitores no distrito $j^{15}$. "A média dos $C j$ entre os eleitorados, ponderada se necessário, é a estimativa $C$, o centrismo do sistema representativo" (Achen 1978, p.487). Quanto menor o valor de $C$, mais próximo o representante estará da média de seus eleitores. Segundo Achen, esta é uma medida da eficiência do 
escala de opinião, do i-ésimo eleitor no $j$-ésimo distrito e $c_{j}$ a opinião média dos eleitores do distrito $j$.

16 Referindo-se aos distritos da Figura 1, Achen afirma que "a intuição sugere que em algum sentido os representantes 2 e 3 são 'eficientes', enquanto o representante 'fora do centro' (off-center) não é" (Achen 1978, p.487).

\footnotetext{
17 Achen toma como base a ideia de que a soberania popular opera a partir do controle dos representantes pelos seus constituintes. E a partir da definição operacional de "controle", chega a essa fórmula (Achen 1978, pp.479-480).
}

$18 \mathrm{O}$ autor apresenta exemplo, utilizando uma figura, comparando o "sistema ideal" a um sistema enviesado, de modo a facilitar o entendimento deste indicador (Achen 1978, pp.490-491). Afirma que métodos ordinários de regressão não podem ser usados para estimar $\alpha$ e $\beta$, sugerindo, em um apêndice, uma forma de superar este problema.

19 Em interessante estudo, Otero-Felipe e Rodrigues-Zepeda (2010) utilizam os três indicadores propostos por Achen para medir congruência na América Latina, tomando como unidade de análise os partidos. representante em diminuir a distância entre sua posição e a posição média de seus constituintes ${ }^{16}$. Ela refletiria a norma democrático-liberal de justiça ou neutralidade em relação às opiniões.

A terceira medida proposta por Achen é responsividade (responsiveness), que derivaria da doutrina liberal da soberania popular: o que o povo decide deve influenciar o resultado. Distritos conservadores devem ser representados por concepções de direita; distritos liberais (no sentido norte-americano) devem ser representados por concepções de esquerda. Se o sistema representativo se adapta às preferências dos cidadãos, a representatividade melhora. A medida é uma estimativa da relação entre preferências dos representantes e preferências dos eleitores e é assim definida:

$$
r=\alpha+\beta \cdot \mu+\varepsilon
$$

onde $r$ exprime a opinião do representante, $\mu$ é a preferência média dos eleitores, $\alpha$ é a posição esperada do representante quando a opinião média do eleitorado é zero e $\beta$ é a mudança esperada na opinião do representante quando a opinião média dos eleitores muda uma unidade; $\varepsilon$ é um termo relativo à variância não explicada ${ }^{17}$. "Dado que a relação de regressão [...] mostra a resposta dos representantes às mudanças na opinião média dos eleitores, nos referimos aos dois parâmetros do modelo, conjuntamente, como 'responsividade' (responsiveness)" (Achen 1978, p.492). Se a relação é forte ( $\beta$ alto) e o valor do componente aleatório é pequeno, pode-se inferir que as preferências do cidadão médio influenciam as opiniões do representante. Um sistema "ideal", em que a representação não é enviesada, é aquele em que $\alpha$ é igual a zero e $\beta$ é igual a um (para escalas que variam de zero a um). Este sistema estabelece o padrão a partir do qual um sistema representativo concreto pode ser compa$\operatorname{rado}^{18}$.

Comparando as medidas, Achen aponta que a responsividade é a medida mais semelhante às correlações (usadas por Miller e Stokes); além disso, alerta que o uso de dados ordinais (procedimento mais comum para medir as preferências) pode gerar viés nas outras duas medidas:

“Algum erro de medição está presente nas respostas dos representantes (a escala ordinal se aproxima do subjacente nível intervalar da atitude apenas imperfeitamente) e isso irá exagerar os escores da proximidade e do centrismo, fazendo com que os congressistas pareçam menos representativos do que são. (As medidas de responsividade são não-viesadas.)" (Achen 1978, p.495) ${ }^{19}$.

Converse e Pierce (1986), em uma monumental obra sobre a representação política na França, embora admitam que os argumentos de Achen contra o uso de correlações estão basicamente corretos, discordam de uma rejeição geral ao uso de correlações no estudo da congruência. Segundo eles, deve-se avaliar o objetivo da análise: "para alguns propósitos a correlação será justamente o que é necessário; para outros ela irá obscurecer e confundir o que se busca" (Converse e Pierce 1986, pp.964-965). Além disso, afirmam que apesar das vantagens advogadas por Achen, sua medida de proximidade tem também uma série de desvantagens:

Primeiro, seria tolice engajar-se em tal subtração entre as posições das elites e das massas a menos que elas fossem mensuradas numa mesma escala [...]. Segundo, dado que os números gerados por tais subtrações deixam deliberadamente de ter o tipo de normalização presente num coeficiente de correlação, elas dificilmente têm algum significado substantivo e isso cria um problema de exposição. Terceiro, esses números, diferentemente de declarações de correlação, não se prestam facilmente a manipulações de segunda ordem semelhantes a correlação parcial e regressão, ou análise de trajetória (path analysis). Quarto, [...] a formação de diferenças absolutas introduz fontes mais fortes de variação 
${ }^{20}$ Medida de congruência semelhante a esta (ou inspirada nela) é utilizada por Belchior (2010, p.79) e Belchior e Freire (2012, p.278). exógena do que normalmente são encontradas nas análises de correlação (Converse \& Pierce 1986, pp.603-604).

Para medir a congruência, os autores acabam por usar tanto correlações como medidas de distância entre as posições de eleitores e de representantes. Uma das medidas de distância é basicamente a diferença entre as posições médias de representantes e eleitores (em relação à escala E-D e uma série de $i s$ sues específicos), mas reescalonando a média das elites em termos de desvios da média dos eleitores, expressos em unidades de desvio-padrão da distribuição dos eleitores (Converse \& Pierce 1986, pp.963-964). O objetivo desse reescalonamento seria facilitar o entendimento, já que coeficientes não-padronizados seriam ininteligíveis para o leitor não especialista em métodos, que não estaria familiarizado com diferenças de escala nas unidades absolutas usadas (Converse \& Pierce 1986, p.958) ${ }^{20}$. Outra medida deste tipo se baseia na "proximidade", proposta por Achen. Os autores a chamam de "'proximidade absoluta' do representante em seu distrito, para diferenciá-la de congruência relativa, para a qual a correlação é um índice natural” (Converse \& Pierce 1986, p.603).

Huber e Powell (1994) utilizam procedimento parecido ao indicador de centrismo formulado por Achen (1978), propondo uma modificação:

"Embora nossas medidas de congruência sejam bastante relacionadas com a medida de 'centrismo' de Achen [...] nós focalizamos o cidadão mediano e não o cidadão médio. Nossa razão para usar a mediana é teórica: se a mediana e a média não coincidem, uma maioria sempre preferirá a mediana à média. Além disso, dado que a média minimiza a soma das distâncias quadráticas, ela dá maior peso a casos mais distantes do centro. Nós não vemos justificativa na teoria democrática para permitir que minorias prevaleçam sobre a maioria, ou para dar maior peso aos cidadãos ideologicamente mais extremos" (Huber \& Powell 1994, p.296).

Vários estudos posteriores seguiram esta formulação (Powell 2000; McDonald, Mendes \& Budge 2004; Belchior 2010; Dalton, Farrell \& McAllister 2011, Budge et al., 2012, Freire \& Belchior 2013, entre outros).

Há, porém, diversas críticas feitas aos métodos que utilizam medidas centrais (médias ou medianas) das preferências de cidadãos e representantes para o cálculo da congruência. Pierce (1999) menciona algumas debilidades desse tipo de procedimento:

"A primeira debilidade é que posições médias das massas e posições médias das elites em relação a temas políticos não são conceitualmente análogas. Os eleitores de um determinado partido não constituem uma entidade operacional da mesma forma como uma elite partidária constitui. Consequentemente, a posição média de uma elite partidária em alguma escala temática (issue scale) significa algo muito diferente daquela dos eleitores na mesma escala [...]. Um partido parlamentar é um grupo real, com padrões regulares de comunicação e capacidade de tomada de decisão. A posição média dos deputados em relação a uma questão é potencialmente convertível em uma política. Nesse sentido, é bastante razoável trabalhar com a posição média das elites [...]. Os eleitores de um determinado partido, porém, não têm tal existência coletiva. Seu escore médio em uma questão não tem realidade [...], nem eles buscam transformá-lo em uma política [...]. A segunda debilidade [...] [é que] a dispersão dos posicionamentos da massa em qualquer escala temática (issue scale) é tipicamente maior do que a dispersão das posições da elite, o que significa que posições médias similares das massas e da elite normalmente refletem distribuições das posições individuais muito diferentes [...]" (Pierce 1999, pp.14-15).

Golder e Stramski (2010) vão formular novas propostas de conceituar (e calcular) congruência, dependendo da quantidade de cidadãos e representantes envolvidos na relação de representação. Dada a influência deste estudo na 
21 Os autores afirmam que "algumas dessas conceituações [...] contêm menos informação do que outras; [...] algumas são mais apropriadas para determinadas questões de pesquisa do que outras. [...] Conceituar congruência vários-para-um em termos da congruência relativa com os cidadãos tem um número de vantagens sobre conceitualizações alternativas" (Golder \& Stramski 2010, p.92).

22 Congruência absoluta com o cidadão mediano (vários-para-um) $=|\mathrm{CM}-\mathrm{G}|$, onde CM é a posição ideológica do cidadão mediano e G é a posição do governo.

${ }^{23}$ Os autores justificam o uso da posição do cidadão mediano, em vez da média das posições dos cidadãos (medida utilizada por Achen 1978) com os mesmos argumentos de Huber e Powell (1994), já mencionados acima.

24 "As áreas sombreadas indicam a distribuição dos cidadãos em uma escala de 0 a 10 relativa a uma dimensão temática (issue dimension) nos países $\mathrm{A}$ e B. X* [...] é a posição do cidadão mediano em cada país. R é a posição do representante dos cidadãos" literatura mais recente, sigo aqui de forma detalhada as maneiras pelas quais os autores definem congruência.

"Acreditamos que a forma como conceituamos congruência depende de estar-
mos pensando sobre (1) um cidadão ou muitos cidadãos e (2) um representante
ou muitos representantes. Nessa perspectiva, podemos pensar em situações nas
quais temos um cidadão e um representante (uma relação um-para-um), situa-
ções nas quais temos vários cidadãos e um representante (uma relação vários-
para-um) e situações nas quais temos vários cidadãos e vários representantes
(uma relação vários-para-vários)" (Golder \& Stramski 2010, p.91).

A partir daí e assumindo, por uma questão de simplicidade, que se trata de uma única dimensão ideológica, Golder e Stramski formulam diferentes maneiras de operacionalizar medidas de congruência. Assim, se o objetivo é medir a congruência entre apenas um eleitor e um representante (relação "um-paraum”), "congruência é apenas a distância absoluta entre as posições ideológicas do cidadão $(\mathrm{C})$ e do representante $(\mathrm{R})$ [...]. Congruência é alta quando a distância absoluta entre o cidadão e o representante é pequena" (Golder \& Stramski 2010, p.92) (ver Figura 2, gráfico a).

Quando o objetivo é medir a congruência entre vários eleitores e um único representante (por exemplo, a relação entre todo o eleitorado e seu governo), trata-se de uma relação "vários-para-um" (many-to-one relationship; ver Figura 2, gráfico b). Há diversas maneiras de operacionalizar este tipo de congruência. Os autores apontam três: 1) congruência absoluta com o cidadão mediano (absolute median citizen congruence); (2) congruência absoluta com os cidadãos (absolute citizen congruence) e (3) congruência relativa com os cidadãos (relative citizen congruence) ${ }^{21}$.

1) Congruência absoluta com o cidadão mediano (vários-para$u m)^{22}$ : mede, basicamente, "o grau de proximidade da posição do representante face à posição preferida dos cidadãos - quanto mais próximo estiver um representante de $\mathrm{X}^{*}$ (posição do cidadão mediano), mais elevado será o nível de congruência" (Golder \& Stramski 2010, p.92) ${ }^{23}$. Esta é a forma mais frequente de medir congruência ideológica na literatura, especialmente quando se trata de estudos comparando diversos países (Huber e Powell 1994; Powell 2000; McDonald, Mendes e Budge 2004; Dalton, Farrel e McAllister 2011; Budge et al., 2012, entre outros). Na Figura 3, "isto implicaria concluir que os representantes dos países A e B são igualmente congruentes, dado encontrarem-se ambos à mesma distância do cidadão mediano (X*)" (Golder \& Stramski 2010, pp.92-93) ${ }^{24}$.

2) Congruência absoluta com os cidadãos (vários-para-um): embora contenha alguma informação, a medida anterior desconsidera as formas de distribuição de preferências entre os eleitores. Esta segunda medida calcula a congruência como a distância média absoluta entre todos os cidadãos (cada um deles) e o representante ${ }^{25}$. Isso nos levaria a concluir que o representante no país A (Figura 3) é mais congruente com seus cidadãos do que o representante no país B (Golder \& Stramski 2010, p.93).

3) Congruência relativa com os cidadãos (vários-para-um): para certos tipos de questão de pesquisa é mais adequado conceituar a congruência não em termos absolutos, mas relativos, isto é, em termos da distância entre os cidadãos e seus representantes, relativamente à dispersão das preferências dos cidadãos (Golder \& Stramski 2010, p.93). Quando se pretende comparar a congruência de diferentes unidades de análise (distritos eleitorais, estados e países), por exemplo, é problemático utilizar as duas medidas anteriores (absolutas). A medida 
Figura 2 - Conceituando congruência ideológica

(a) Relação Um-para-Um

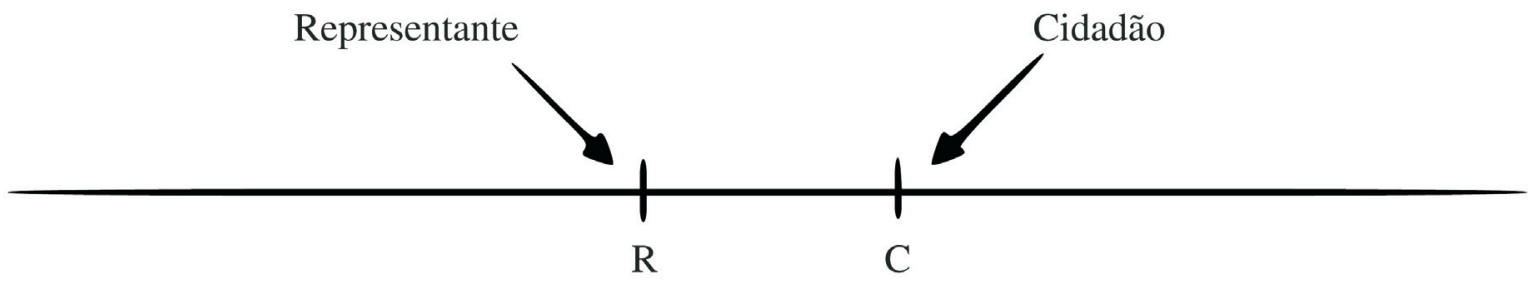

(b) Relação Muitos-para-Um

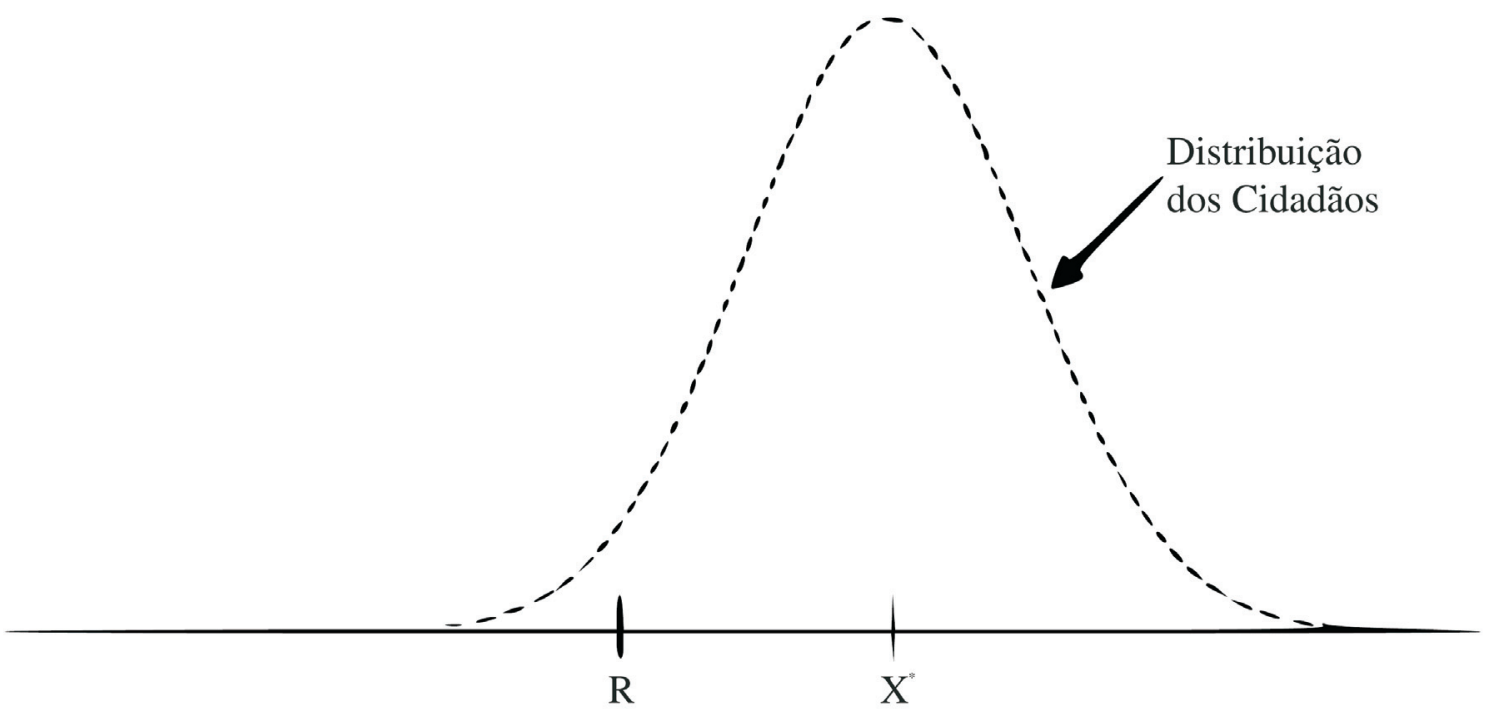

(c) Relação Muitos-para-Muitos

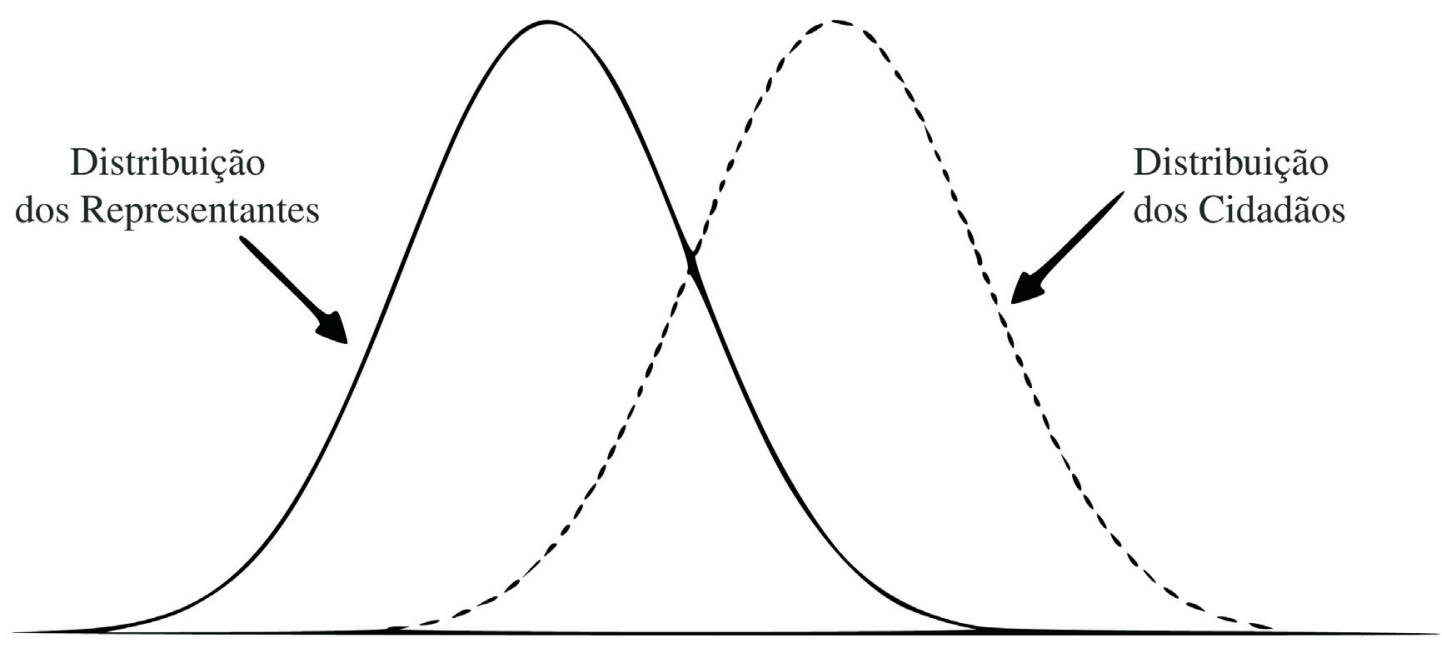

Fonte: O autor, a partir de Golder e Stramski (2010, p.91). 
Figura 3 - Congruência ideológica em relações vários-para-um

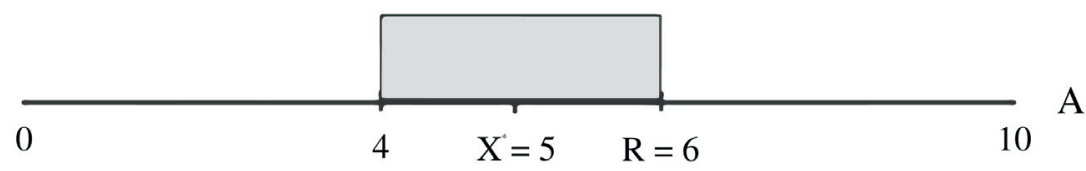

Fonte: O autor, a partir de Golder e Stramski (2010).

(Golder \& Stramski 2010, p.92).

${ }^{25}$ Congruência absoluta com os cidadãos (vários-para-um) $=1 / N\left(\Sigma C_{i}-G\right)$, onde $N$ é o número de cidadãos, $C_{i}$ é o ponto ideal do $i$-ésimo cidadão e $G$ é a posição do governo. A medida é semelhante à de proximidade de Achen. Nesta última, porém, as diferenças entre as posições de cada cidadão e de seu representante são elevadas ao quadrado. de congruência absoluta com os cidadãos "beneficia" os representantes de eleitorados mais homogêneos (como os do país A na Figura 3). O nível máximo de congruência absoluta é atingido quando o representante se situa na posição do cidadão mediano. Supondo que o representante do país B passasse a se situar em $\mathrm{X}^{*}$, ainda seria menos congruente com seu eleitorado, em termos absolutos, do que o representante do país A: "este é o caso, mesmo que o representante no país B não possa aumentar mais sua congruência [...] e mesmo que o representante 'mais congruente' no país A mantenha a mais extrema posição em seu país" (Golder \& Stramski 2010, p.94).

Se o objetivo de nosso estudo for comparar a capacidade de os representantes gerarem a máxima congruência possível com seu eleitorado, usar a medida de congruência absoluta com os cidadãos levaria a conclusões equivocadas. O mais adequado é conceber a congruência em termos da distância entre os cidadãos e seu representante em função da dispersão das preferências dos cidadãos em cada caso (no exemplo, os países A e B), ou seja, usar uma medida de congruência relativa com os cidadãos. A medida é assim definida:

$$
\begin{aligned}
& \text { Congruência relativa com os cidadãos (vários-para-um) }= \\
& 1-\left(\Sigma\left|C_{i}-M C\right| / \Sigma\left|C_{i}-G\right|\right),
\end{aligned}
$$

onde $C_{i}$ é o ponto ideal do $i$-ésimo cidadão, $M C$ a posição do cidadão mediano e $G$ é a posição do governo. Segundo os autores,

\footnotetext{
"esta medida de congruência relativa com os cidadãos varia de 0 a 1. [...]. Quanto mais distante a posição do governo estiver de $M C$, mais próxima a congruência relativa com os cidadãos estará de 1 . Na realidade, a medida captura a distância média entre um cidadão e a posição mais preferida dos cidadãos $(M C)$, relativamente à distância média entre um cidadão $(C)$ e o governo $(G)$. Quanto menor o escore em todas as três medidas, melhor a congruência entre eleitores e seu governo (Golder \& Stramski 2010, p. 96).
}

Outro problema apontado pelos autores se refere ao uso de escalas E-D: o uso de medidas absolutas a partir dos posicionamentos E-D de cidadãos e representantes só poderia ser adequado se esta dimensão temática fosse percebida da mesma forma nas várias unidades de análise (diferentes países, por exemplo). O uso da medida de congruência relativa, ao padronizar a congruência por referência à dispersão dos cidadãos, "provê um conceito de congruência livre de qualquer métrica (metric-free). Desta forma, evita potenciais dificuldades com Funcionamento Diferencial dos Itens (DIF) que podem surgir se a escala E-D 
não for percebida da mesma forma em diferentes países" (Golder \& Stramski 2010, p.94).

Os autores afirmam que julgam esta última como a forma mais adequada de mensurar a congruência "vários-para-um", dado que ela permite tanto considerar informação referente à distribuição completa das preferências dos cidadãos, como evitar problemas de DIF. Porém, admitem que outros investigadores possam ter opinião diferente. De toda forma, chamam a atenção para o fato de que a opção por uma das formas de operacionalizar o conceito de congruência afeta os resultados dos estudos. Retomando o exemplo dos dois países apresentados na Figura 3, indicam: 1) que os representantes dos países A e B poderiam ser considerados igualmente congruentes em relação ao seu eleitorado, caso seja usada a medida de congruência absoluta com o cidadão mediano; (2) que o representante do país A seria considerado o mais congruente usando a congruência absoluta com os cidadãos; (3) que o representante do país B seria considerado o mais congruente, a partir da medida de congruência relativa aos cidadãos. Alertam, portanto, para a necessidade de os estudiosos justificarem o uso das medidas que acabam por escolher, já que essa escolha acaba por afetar os resultados.

Por fim, seguindo Golder e Stramski (2010), se o objetivo é medir congruência entre os eleitores (em conjunto) com o corpo legislativo como um todo (relação "vários-para-vários"), então o mais adequado seria comparar a distribuição (inteira) de preferências dos eleitores (não só a posição do eleitor mediano) com a distribuição (inteira) de preferências dos legisladores (não só com as preferências de um único representante, e.g., o governo), como nos casos anteriores, ou mesmo com as do representante mediano. A preocupação seria saber se as diferentes preferências estão representadas em proporção à sua dimensão no eleitorado. Como os autores notam, essa ênfase na importância de um corpo representativo cujas preferências correspondam com precisão às da nação no seu todo aparece em autores clássicos que refletiram sobre a representação, como Mirabeau, Edmund Burke e John Stuart Mill, entre outros.

Os autores operacionalizam esta medida por meio da fórmula:

Congruência (vários-para-vários $)=\sum\left|F_{1}(x)-F_{2}(x)\right|$, onde

" $F_{1}(x)$ e $F_{2}(x)$ são as Funções de Distribuição Cumulativas (CDFs) para as preferências dos cidadãos e dos representantes. Essencialmente, esta medida captura a área entre as CDFs para os cidadãos e os representantes. Quando as preferências ideológicas de cidadãos e representantes estão identicamente distribuídas numa dimensão E-D, então a área entre suas CDFs será zero. Nesta situação, a congruência vários-para-vários será perfeita. À medida que as distribuições de cidadãos e representantes começam a diferir, [...] então a área entre as CDFs aumentará, indicando um declínio na congruência muitos-para-muitos (Golder \& Stramski 2010, p.96) ${ }^{26}$.

Ver Figura A1, no Apêndice, para uma comparação dos níveis de congruência em três países hipotéticos a partir das distribuições de preferências de cidadãos e representantes em cada país.
Os autores fazem uma analogia entre sua medida de congruência "váriospara-vários" e as medidas de desproporcionalidade entre votos e cadeiras, muito utilizadas em estudos comparativos de representação. Enquanto estas últimas indicam se os diferentes partidos receberam cadeiras proporcionalmente ao número de votos que obtiveram, aquele indicador de congruência permitiria avaliar em que medida as preferências políticas dos representantes refletiriam a distribuição de preferências dos eleitores.

A proposta de Golder e Stramski (2010) tornou-se bastante influente na literatura mais recente. Um interessante estudo que tenta aprimorar tal metodologia para a análise da congruência em um tipo de relação vários-para-vários é o de Andeweg (2011). 
27 Para a transformação de escalas E-D, visando comparar escalas com diferentes números de pontos na escala, ver Andeweg (2011, p.42) e Power e Zucco Jr. (2009).

28 São reproduzidas apenas as figuras correspondentes ao primeiro e ao último survey (1972 e 2006) aplicados simultaneamente a eleitores e representantes analisados por Andeweg (2011). A congruência aumentou de $60 \%$, em 1972, para $89,3 \%$ em 2006. Andeweg (2011) também mostra que a distribuição de preferências dos representantes é que se aproximou da dos eleitores, ao longo do tempo (representation from below).

${ }^{29}$ Os autores definem “quantização" (quantization) como o processo de restringir uma quantidade contínua a valores discretos (o que representa perda de informação).

${ }^{30}$ Lupu, Selios e Warner (2017) criticam ainda a análise de Procrustes (procrustes analysis) utilizada por Luna (2014), pois embora este tipo de análise permita medir congruência em espaços multidimensionais, também apresentaria diversas limitações, algumas semelhantes às das "medidas de superposição".

31 Nesse caso, não havendo superposição alguma entre a distribuição X e a parte relativa à segunda "normal" da distribuição Y3, o valor de congruência seria o mesmo, qualquer que fosse aquele valor médio (e a distribuição dos valores em torno dele).
O autor compara as posições de eleitores e parlamentares (numa escala E-D e em relação a cinco questões específicas) obtidas por meio de surveys, em cinco instantes entre 1972 e 2006, utilizando as distribuições completas das preferências (como proposto por Golder e Stramski 2010), em vez de comparar as preferências médias ou medianas ${ }^{27}$. No cálculo da congruência, porém, enquanto Golder e Stramski (2010) comparam as funções de distribuição cumulativas das posições de eleitores e representantes, Andeweg (2011) compara diretamente a porcentagem de eleitores que se posicionam em um ponto da escala (de sete pontos) com a porcentagem de parlamentares que se posicionam nesse mesmo ponto, tomando a menor das duas porcentagens (ver Figura 4). Somando-se as sete porcentagens (mínimo percentual comum entre eleitores e representantes, em cada um dos pontos da escala), obtém-se a superposição (overlap) entre as duas distribuições ("a área comum sob a curva"). A medida varia entre zero (nenhuma superposição entre as duas distribuições, nenhuma congruência) e 100 (distribuições idênticas, congruência política completa). Trata-se de uma medida mais simples de calcular e mais intuitiva do que a proposta por Golder e Stramski (2010) ${ }^{28}$.

Recentemente, Lupu, Selios e Warner (2017) formularam outra medida para os estudos de congruência ideológica, a Earth Mover's Distance. Os autores criticam medidas como as propostas por Golder e Stramski (2010) e Andeweg (2011) para o cálculo da congruência "vários-para-vários": essas "medidas de superposição" (overleap measures) requereriam decisões arbitrárias sobre "quantização" 29 , limitariam a comparação entre massas e elites a uma única dimensão e ignorariam muita informação presente nos dados ${ }^{30}$.

A Figura 5, reproduzida do artigo em questão, ilustra este último problema. Ela mostra a comparação entre uma hipotética distribuição de frequências de uma variável X e três diferentes hipotéticas distribuições de frequência (Y1, Y2 e Y3) de uma variável Y. Como as medidas de Golder e Stramski (2010) e de Andeweg (2011) são calculadas apenas com base nas partes das distribuições que se superpõem, elas acabam por ignorar toda a informação existente nas partes não superpostas. Assim, por exemplo, considerando-se apenas o painel inferior da Figura 5, não importaria, para as medidas de distância entre as distribuições de X e Y3, se o valor médio da segunda "normal" (que caracteriza a distribuição bimodal Y3) estivesse no valor 12, 15 ou 20 - desde que toda a distribuição em torno dessa segunda "normal" não tivesse superposição alguma com a distribuição $\mathrm{X}^{31}$. Entretanto, parece evidente que uma medida adequada deveria resultar numa distância menor caso a distribuição Y3 tivesse, como média da segunda "normal", o valor 12 (não 15 ou 20).

Visando eliminar estes problemas, Lupu, Selios e Warner (2017) propõem o uso da Earth Mover's Distance (EMD) - uma medida que, embora não tivesse sido adotada (até ali) na Ciência Política, é utilizada em várias outras aplicações, tendo se originado na solução de um problema de alocação de recursos em transportes (Monge 1781). Esta medida, segundo os autores, eliminaria os problemas apontados nas "medidas de superposição" mencionadas ao utilizar todos os dados das distribuições (não ignorando os valores das distribuições que não se superpõem) e podendo ser calculada como uma medida sintética de múltiplas questões, preferências ou dimensões políticas.

Um problema desta medida é sua maior complexidade. Não se pretende aqui recuperar todos os passos traçados pelos autores para explicar o significado e a forma de cálculo da medida. Basicamente, considere-se as distribuiçõos de valores de duas variáveis X e Y; a EMD entre X e Y é definida pela solução de um problema linear de otimização, o ótimo "fluxo" $\left(f_{i j}\right)$ para "mover" a distância entre os valores de $\mathrm{X}$ e $\mathrm{Y}$, de tal forma que estes se "igualem” àqueles. 
Figura 4 - Congruência política coletiva entre eleitores e representantes numa escala Esquerda-Direita - 1972 e 2006 (Holanda)

a. $1972 / 1972$
congruência
$U$ representantes
Oeleitores

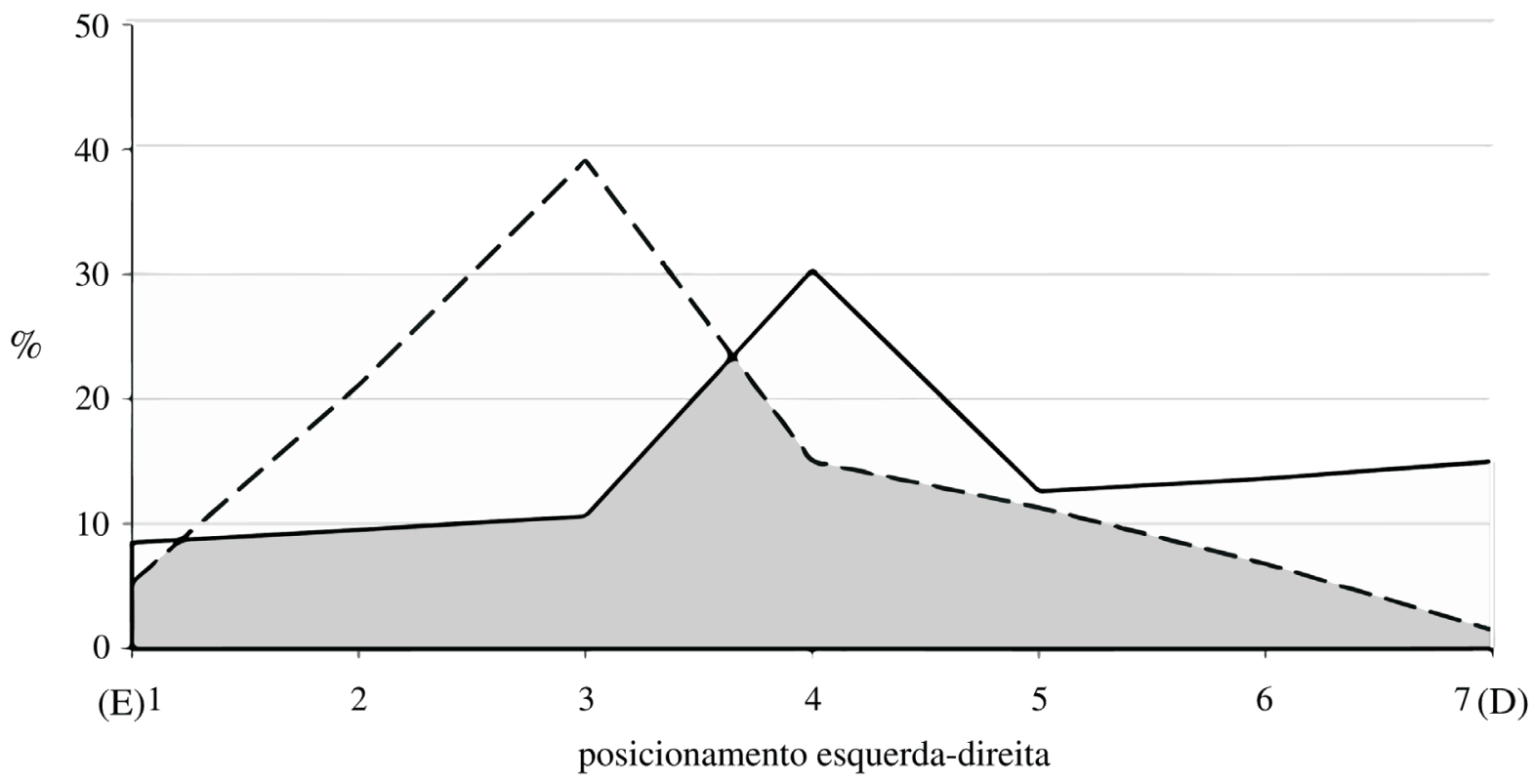

Nota: Área comum sob a curva $=60 \%$ (Eleitores $-\mathrm{N}=1136$; Representantes $-\mathrm{N}=133$ )

b. $2006 / 2006$

congruência U representantes Q eleitores

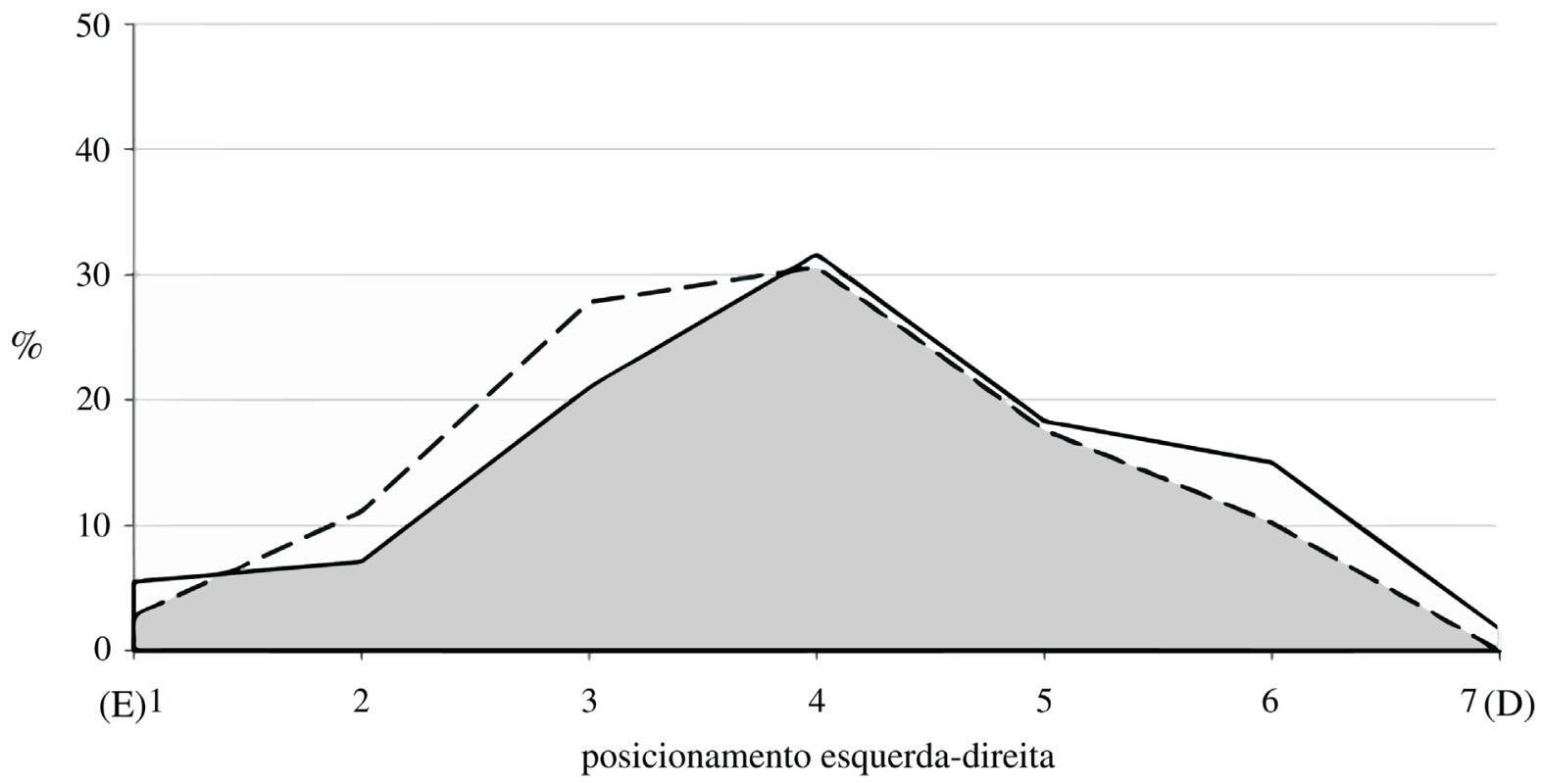

Nota: Área comum sob a curva $=89,3 \%$ (Eleitores - N = 2345; Representantes - N = 108)

Fonte: O autor, a partir de Andeweg (2011). 
Figura 5 - Três hipotéticas comparações de distribuições usando dados simulados
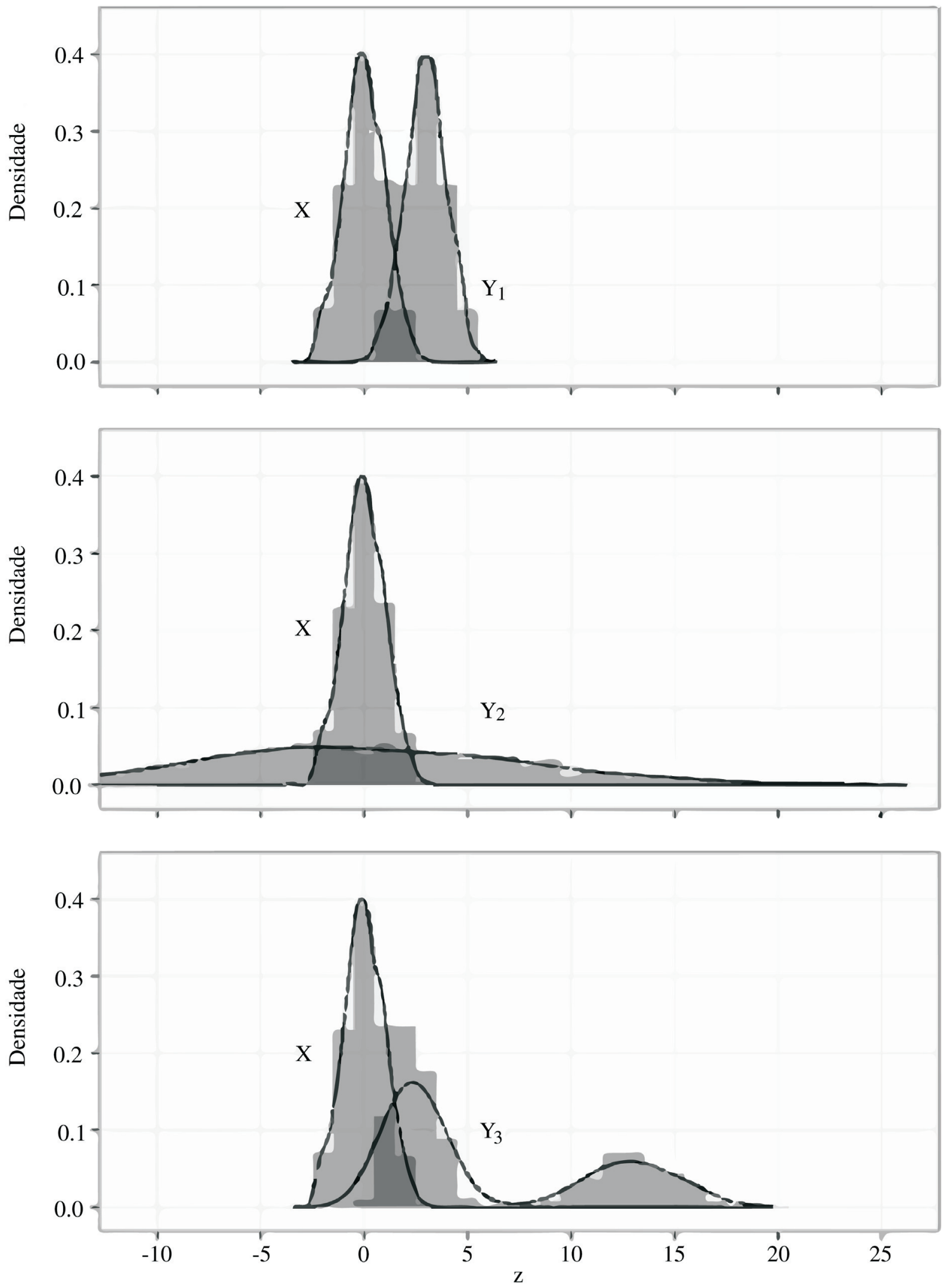

Fonte: Lupu, Selios e Warner (2017).

Nota: Uma boa medida de distância deveria ao menos indicar que as distribuições no painel mais acima são as mais similares. 
32 A fórmula simplificada de EMD (válida para os casos mais típicos dos estudos de congruência) é EMD $=\Sigma f_{i j} \| x$ - $y_{j}$ ll (ver Lupu, Selios e Warner 2017, p.103, equação 10).
Suponhamos que se deseje calcular o EMD entre duas distribuições de posicionamentos de respondentes (em duas amostras) em uma escala de 0 a 10 (p.ex., os posicionamentos de eleitores e representantes numa escala E-D). Esses posicionamentos podem ser representados por $P_{x}=\{(2,0,5),(5,0,3),(8$, $0,2)\}$ e $P_{y}=\{(4,0,3),(5,0,4),(6,0,3)\}$. O primeiro valor entre parênteses indica o ponto na escala e o segundo valor o "peso", "massa" ou "densidade", ou seja, a porcentagem de indivíduos que "ocupam" aquele valor. Isso significa que esta seria a distribuição de $\mathrm{X}$ (p. ex., posicionamentos de eleitores na escala E-D): $50 \%$ dos indivíduos estariam no ponto 2 da escala, $30 \%$ no ponto 5 e $20 \%$ no ponto 8. Quanto à distribuição de Y (p. ex., posicionamentos de representantes na escala E-D): $30 \%$ dos indivíduos estariam no ponto 4 da escala, $40 \%$ no ponto 5 e $30 \%$ no ponto 6 .

O objetivo é encontrar o "fluxo ótimo" (optimal flow) capaz de minimizar o "trabalho" para "mover" os valores de X, de forma que eles se "igualem" aos de Y. A Figura 6 apresenta dois possíveis "fluxos" para "mover" os valores de X até eles se igualarem aos de Y. O primeiro é o "fluxo ótimo", que se inicia por "deslocar" dados em $\mathrm{P}_{\mathrm{x}}$, em que $\mathrm{z}=2$ para $\mathrm{z}=4$ até o peso total de $0,3(30 \%)$. Este processo produziria um "trabalho" de 1,7:

$$
\begin{aligned}
& (|4-2|)(0,3)+(|5-5|)(0,3)+(|5-2|)(0,1)+(|6-2|)(0,1) \\
& +(|6-8|)(0,2)=1,7^{32}
\end{aligned}
$$

Outros fluxos podem levar ao mesmo resultado, mas requerem mais "trabalho". O segundo painel mostra um possível "fluxo ineficiente", produzindo um "trabalho" total de 2,5 (resultado obtido a partir de cálculo similar ao acima). $\mathrm{Na}$ realidade, é necessário que um programa calcule os mais diversos fluxos possíveis para realizar isso, de forma a achar aquele que corresponderia ao menor "trabalho", ou seja, o "fluxo ótimo" (Figura 6).

De forma a demonstrar a superioridade da EMD em relação às medidas mais usuais de congruência utilizadas na Ciência Política, Lupu, Selios e Warner (2017) comparam valores calculados a partir de quatro medidas, simulando valores para as três situações apresentadas na Figura 5. As medidas são a diferença de médias (DM, equivalente à medida de congruência "um-paraum"), as duas "medidas de superposição" "muitos-para-muitos", propostas por Golder e Stramski (2010) e Andeweg (2011) - Cumulative Distribution Function (CDF) e Probability Density Function (PDF), respectivamente - e a EMD. A expectativa é que uma boa medida de distância calcule um valor menor para a situação 1 (em que as distribuições são mais similares). Do cálculo da DM e $\mathrm{CDF}$, porém, resulta uma menor distância na situação 2 , enquanto, do cálculo da PDF, resulta como menor distância a situação 3. Só com base na EMD o resultado aponta, como menor distância entre as duas distribuições, a situação 1. Também a partir de um experimento de Monte Carlo, os autores mostram que a EMD é a medida que (comparativamente às demais) garante o que julgam ser "a mais importante rubrica para avaliar uma medida": sua capacidade de preservar a ordinalidade (das distâncias comparadas) - além da cardinalidade, que seria uma característica secundária.

Lupu, Selios e Warner (2017) ainda utilizam o EMD para testar hipóteses em dois debates relevantes na literatura, para mostrar sua utilidade. A partir da EMD, analisam dados relacionando sistemas eleitorais e congruência ideológica, concluindo que "quando substituímos a problemática medida CDF pela EMD não encontramos evidência convincente de que legislaturas em sistemas eleitorais proporcionais refletem melhor as preferências ideológicas dos cidadãos" (Lupu, Selios e Warner 2017, p.108). Da mesma forma, ao medir congruência entre massas e elites na América Latina, contrariando alguns estudos prévios, não se encontrou relação entre o grau de institucionalização do sistema partidário e o grau de congruência alcançado. 
Figura 6 - Dois exemplos de "fluxo"

Fluxo ótimo

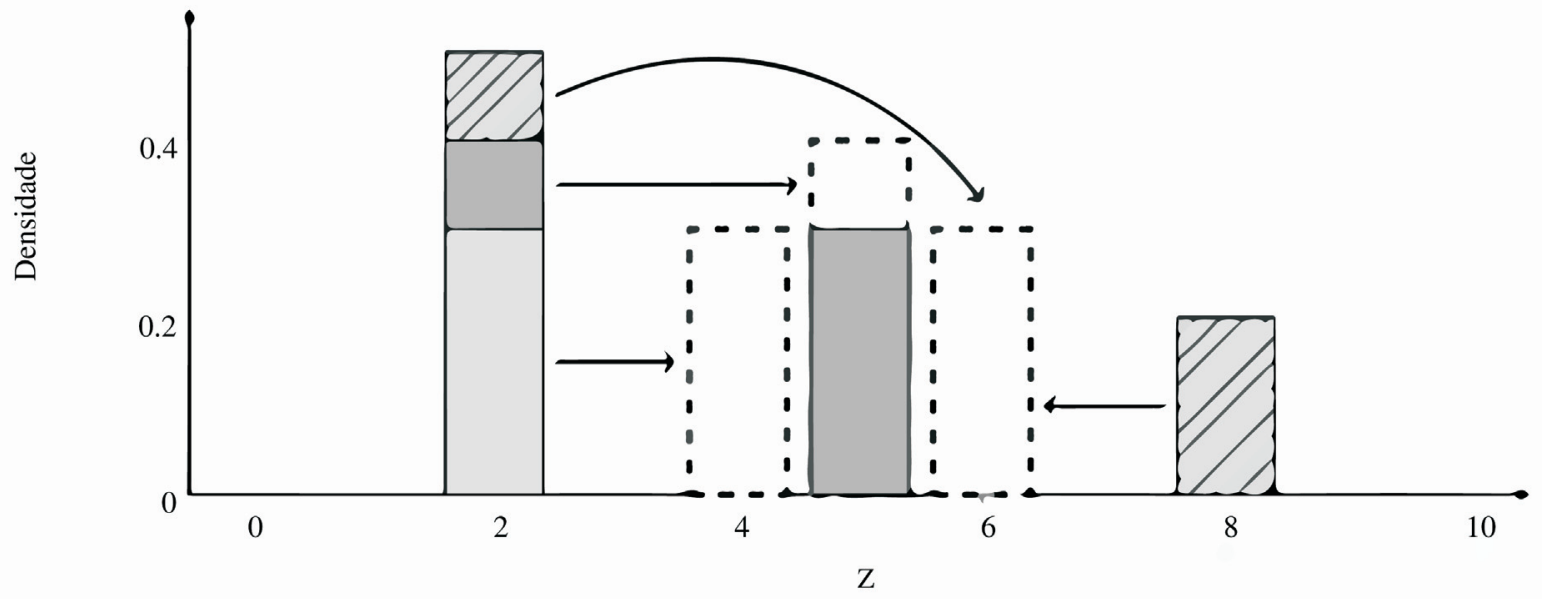

Fluxo ineficiente

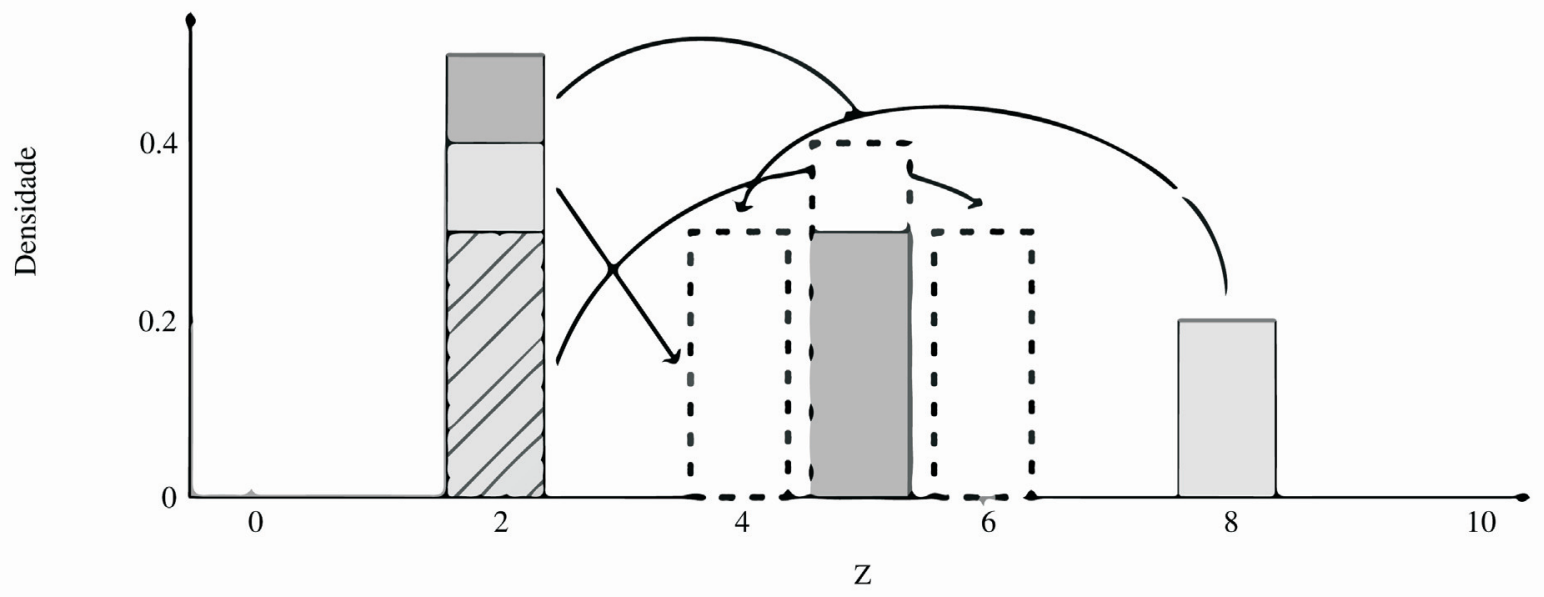

Fonte: Lupu, Selios e Warner (2017, p.102).

Nota: Px está em cinza, enquanto Py em linhas tracejadas. Dados plotados em cinza claro "acabam" em z = 4, em cinza escuro em $\mathrm{z}=5$ e em listras em $\mathrm{z}=6$. No painel superior, os dados em Px são deslocados para a posição mais próxima disponível, resultando num trabalho total de 1,7. No painel inferior um fluxo menos eficiente resulta em mais trabalho $(2,5)$. A EMD encontra o fluxo ótimo que minimiza o trabalho.

Ao final, os autores concluem: a EMD dá uma medida mais acurada da congruência do que as medidas que vêm sendo utilizadas na Ciência Política. A EMD deveria se tornar a medida padrão a ser usada para computar a distância entre as preferências de massas e elites.

O Quadro 1 apresenta uma síntese da evolução dos trabalhos que formularam as principais medidas de congruência presentes no debate resenhado acima.

\section{Conclusões}

A literatura internacional que estuda, empiricamente, os processos de representação política e os estudos de congruência entre as preferências de eleitores e representantes tem um papel de grande destaque. Este artigo apresentou as 
Quadro 1 - Evolução das principais medidas de congruência

\begin{tabular}{|c|c|}
\hline Trabalho & Medidas de Congruência \\
\hline $\begin{array}{l}\text { Miller e Stokes } \\
(1963)\end{array}$ & $\begin{array}{l}\text { Correlação entre posicionamentos de eleitores e } \\
\text { representantes }\end{array}$ \\
\hline Achen $(1977 ; 1978)$ & $\begin{array}{l}\text { Medidas de distância entre representantes e eleitores: } \\
\text { proximidade, centrismo e responsividade }\end{array}$ \\
\hline $\begin{array}{l}\text { Converse e Pierce } \\
\text { (1986) }\end{array}$ & $\begin{array}{l}\text { Correlações e medidas de distância entre representantes e } \\
\text { eleitores (adaptadas de Achen) }\end{array}$ \\
\hline $\begin{array}{l}\text { Huber e Powell } \\
\text { (1994) }\end{array}$ & $\begin{array}{l}\text { Adaptação da medida de centrismo de Achen (usando } \\
\text { posições do cidadão mediano, no lugar do cidadão médio) }\end{array}$ \\
\hline $\begin{array}{l}\text { Golder e Stramski } \\
(2010)\end{array}$ & $\begin{array}{l}\text { a) relação um-para-um: congruência = distância absoluta en- } \\
\text { tre as posições ideológicas do cidadão e do representante b) } \\
\text { relação "vários-para-um": diversas maneiras de } \\
\text { operacionalizar este tipo de congruência: } 1 \text { ) congruência } \\
\text { absoluta com o cidadão mediano; (2) congruência absoluta } \\
\text { com os cidadãos e (3) congruência relativa com os cidadãos c) } \\
\text { relação "vários-para-vários": compara a distribuição inteira } \\
\text { de preferências dos cidadãos com a distribuição inteira de } \\
\text { preferências dos legisladores (e não apenas as posições } \\
\text { medianas). Cálculo a partir de Funções de Distribuição } \\
\text { Cumulativas (CDFs) }\end{array}$ \\
\hline Andeweg (2011) & $\begin{array}{l}\text { Adaptação de medida de Golder e Stramski (2010) para a } \\
\text { relação "vários-para-vários" (distribuições inteiras de } \\
\text { preferências), comparando diretamente as porcentagens de } \\
\text { cidadãos e parlamentares em cada ponto da escala (no lugar } \\
\text { das CDFs) }\end{array}$ \\
\hline $\begin{array}{l}\text { Lupu, Selios e } \\
\text { Warner (2017) }\end{array}$ & Earth Mover's Distance \\
\hline
\end{tabular}

Fonte: $\mathrm{O}$ autor.

principais vantagens e desvantagens atribuídas às formas mais usuais de operacionalização das estimativas das preferências políticas de eleitores e representantes, bem como das medidas de congruência. Sem a pretensão de chegar a uma conclusão sobre qual "a" forma mais adequada de fazer essas operacionalizações, destaca-se, a seguir, alguns dos pontos mais importantes.

Das múltiplas formas possíveis para estimar as posições políticas de cidadãos e representantes, a forma mais adequada parece ser estimar suas posições perguntando, diretamente, as mesmas questões em surveys usando uma escala E-D (como em Andeweg 2011, Holmberg 2011 e Freire \& Belchior 2013), ou questões de temas específicos, com opções de resposta na forma de escalas (podendo-se criar índices a partir das respostas a certas baterias de questões). Quando possível, estas parecem ser as estratégias com mais potencial de evitar vários problemas apontados na Seção 3.

Um dos principais problemas de usar avaliações de experts, ou o posicionamento estimado de um partido a partir da metodologia do Comparative Manifestos Project para estimar as posições dos representantes, é que a pressuposição operacional de que todos eles têm a mesma posição de seus partidos ignora as variações ideológicas entre legisladores de um mesmo partido. Ainda mais problemático seria estimar a posição dos representantes (ou, mais precisamente, de seus partidos) a partir das percepções dos eleitores a respeito daquela posição. Isso tenderia a enviesar os resultados à congruência, já que os eleitores podem "projetar", no partido com o qual se identificam, suas próprias posições. De toda forma, as restrições relativas aos dados têm um papel decisivo nessas 
escolhas, já que algumas das fontes e tipos de informação podem não estar disponíveis ao pesquisador em determinado momento e local.

Vários trabalhos (Achen 1978; Converse \& Pierce 1986; Powell 2009; Golder \& Stramski 2010; Belchior 2010; Andeweg 2011; Belchior \& Freire 2012) afirmam que diferentes formas de conceituar e operacionalizar as medidas de congruência podem levar a conclusões muito diversas e, por isso, é importante justificar criteriosamente as formas a serem adotadas. Um ponto central neste debate são as medidas de congruência absolutas ou relativas. Embora cada tipo de medida tenha suas vantagens e desvantagens, parece haver uma preferência por este último tipo de medidas por parte de vários autores, entre os quais Achen (1978), Converse e Pierce (1986), Golder e Stramski (2010) e Belchior e Freire (2012). Estes últimos apontam que a principal questão relativa à mensuração de congruência coletiva desde Achen (1978) até Golder e Stramski (2010), é decidir se devemos usar medidas relativas ou absolutas de congruência. E apresentam uma boa síntese das diferenças em jogo:

"Congruência absoluta tem as vantagens de que os cálculos são simples e a interpretação dos resultados é intuitiva. Congruência relativa é geralmente melhor em termos da validade das medidas, dado que leva a dispersão dos eleitores em consideração; dessa forma, é possível tanto controlar as distribuições dos eleitores em cada partido quanto comparar melhor a congruência entre partidos" (Belchior \& Freire 2012, p.277).

Quanto à escolha entre a comparação entre o uso de médias (ou medianas) das posições de eleitores e representantes, por um lado, e o uso de medidas que comparem a distribuição completa das preferências dos dois grupos de atores envolvidos na relação de representação, de outro, caso o objetivo seja apenas verificar se o parlamento como um todo (ou o governo) tem preferências em consonância com as preferências médias (ou medianas) dos cidadãos, o primeiro tipo de medida pode ser suficiente.

O segundo tipo (congruência "vários-para-vários") é uma alternativa mais adequada se a preocupação for verificar se as diferentes preferências, no eleitorado, estão proporcionalmente representadas por preferências semelhantes entre os legisladores. Dos trabalhos alinhados a esta última perspectiva, vale a pena destacar os procedimentos utilizados por Andeweg (2011). Este estudo (1) usa medidas diretas de preferências de eleitores e representantes, a partir de surveys com questões semelhantes para os dois grupos, em vez de se basear em alguma proxy; (2) usa tanto a escala E-D quanto issues específicos; (3) estuda representação coletiva, comparando as preferências de todo o eleitorado e do parlamento como um todo, mas também os eleitores de cada partido com os representantes destes partidos; (4) compara as distribuições completas das preferências de eleitores e representantes, em vez de comparar as preferências médias ou medianas; (5) sua forma de calcular a congruência parece mais simples e intuitiva do que a proposta por Golder e Stramski (2010); (6) como dispunha de dados para cinco diferentes momentos, verificou a evolução do grau de congruência ao longo do tempo e, a partir daí, formulou hipóteses causais, como as derivadas da constatação de que o aumento da congruência na Holanda, entre 1972 e 2006, deu-se porque a distribuição de preferências ideológicas dos representantes foi se aproximando da dos eleitores, não o contrário.

A recente proposta de Lupu, Selios e Warner (2017), porém, deve ter grande repercussão no futuro próximo. Ela parece indicar um caminho mais complexo, mas mais robusto para o cálculo da congruência, na medida em que elimina problemas como a perda de informações relativas às distribuições completas de preferências dos eleitores e seus representantes. 
De toda forma, é preciso mencionar que vários pesquisadores têm feito uso, proveitosamente, de várias das abordagens aqui mencionadas para cálculo da congruência, às vezes num mesmo estudo - como é o caso de Achen (1978), Golder e Stramski (2010), Otero-Felipe e Rodrigues-Zepeda (2010), Belchior (2010); Belchior e Freire (2012), Freire e Belchior (2013), entre outros.

Além disso, também quanto à unidade de análise, há variações: alguns estudos estimam preferências e calculam a congruência tomando como unidade de análise os partidos, a partir do "modelo do partido responsável" (OteroFelipe \& Rodrigues-Zepeda 2010; Belchior \& Freire 2012), enquanto outros analisam a congruência entre cidadãos e representantes em âmbito mais amplo, do Legislativo como um todo. Outros, ainda, analisam a congruência simultaneamente, a partir dessas diferentes unidades de análise, e utilizando diversas medidas (Belchior 2010; Freire \& Belchior 2013).

Por fim, há um forte consenso no sentido de que diferentes formas de conceituar e operacionalizar as medidas de congruência entre eleitores e representantes podem levar a conclusões muito diversas e, por isso, é importante escolher e justificar criteriosamente as formas a serem adotadas. Cada uma tem suas vantagens e desvantagens, dependendo do tipo de preocupação normativa, da questão empírica privilegiada e os tipos de dados disponíveis. Ao mesmo tempo, isso não significa que todas as formas sejam igualmente boas para o mesmo objetivo. Isso justifica a expectativa de que esta revisão do debate metodológico possa contribuir para um maior discernimento das limitações e potencialidades dos diferentes procedimentos em um tipo de estudos tão importante para a compreensão da representação política, ainda tão escasso no país.

IY an de Souza Carreirão (yancarreirao@uol.com.br) é Doutor em Ciência Política pela Universidade de São Paulo (USP) e Professor do Departamento de Sociologia e Ciência Política da Universidade Federal de Santa Catarina (UFSC). Vínculo Institucional: Departamento de Sociologia e Ciência Política, UFSC, Florianópolis, SC, Brasil.

\section{Referências}

Achen, C., 1977. Measuring Representation: Perils of the correlation coefficient. American Journal of Political Science, 21(4), pp.805-815. DOI: $10.2307 / 2110737$

Achen, C, 1978. Measuring Representation. American Journal of Political Science, 22(3), pp.475-510. DOI: 10.2307/2110458

Aldrich, J. \& McKelvey, R.D., 1977. A Method of Scaling with Applications to the 1968 and 1972 Presidential Elections. American Political Science Review, 71(1), pp.111-130. DOI: 10.2307/1956957

Almeida, A., 2001a. Ideologia e comportamento eleitoral: evidências de que a ideologia não é importante para explicar o voto. In XXV Encontro Anual da ANPOCS. Caxambu.

Almeida, A., 2001b. À esquerda dos números, à direita dos fatos. Insight Inteligência, 15, pp.113- 128.

Ames, B.; Pereira, C. \& Rennó, L., 2011. Famintos por pork. Uma análise da demanda e da oferta por políticas localistas e suas implicações para a representação política. In T. Power \& C. Zucco JR., eds. O Congresso por ele mesmo. Autopercepções da classe política brasileira. Belo Horizonte: Ed. UFMG

Andeweg, R., 2011. Approaching Perfect Policy Congruence: Measurement, development, and relevance for political representation. In M. Rosema; B. Denters \& K. Aarts, eds. How Democracy Works: Political representation and policy congruence in modern societies. Amsterdam: Pallas Publications.

Arrow, K., 1951. Social Choice and Individual Values. New York: Wiley.

Belchior, A.M., 2010. Democracia e representação partidária. A elite parlamentar e os cidadãos. Lisboa: Imprensa de Ciências Sociais.

Belchior, A.M. \& Freire, A., 2012. Is Party Type Relevant to an Explanation of Policy Congruence? Catchall vs. ideological parties in the Portuguese case. International Political Science Review, 34(3), pp.273-288. DOI: $10.1177 / 0192512112467215$

Boas, T. \& Smith, A.E., 2016. Looks Like Me, Thinks Like Me? Descriptive representation and opinion congruence in Brazil. In Annual Meeting of the Midwest Political Science Association. Chicago.

Bornschier, S., 2013. Trayectorias históricas y responsiveness del sistema de partidos en siete países de América Latina. América Latina Hoy, 65, pp.45-77. DOI: 10.14201/alh2013654577

Budge, I.; Klingemann, H-D.; Volkens, A.; Bara, J. \& Tanenbaum, E., 2001. Mapping Policy Preferences: Estimates for parties, electors, and governments - 1945-1998. New York: Oxford University Press. 
Budge, I.; Keman, H.; Mcdonald, M. \& Pennings, P., 2012. Organizing Democratic Choice: Party representation over time. Oxford: Oxford University Press.

Carreirão, Y., 2002. A decisão de voto nas eleições presidenciais brasileiras. Florianópolis/Rio de Janeiro: Editora da UFSC/FGV.

Carreirão, Y., 2015. Representação política como congruência entre as preferências dos cidadãos e as políticas públicas: uma revisão da literatura internacional. Opinião Pública, 21(2), pp.393-430. DOI: 10.1590/1807-01912015212393

Colomer, J.M. \& Escatel, L., 2005. La dimensión izquierda-derecha em América Latina. Desarrollo Económico, 44(177), pp.123-136. DOI: $10.2307 / 3655894$

Converse, P.E. \& Pierce, R., 1986. Political Representation in France. Cambridge, MA: Harvard University Press.

Dahl, R., 1997. Poliarquia. São Paulo: Edusp.

Dalton, R., 2008. Citizen Politics: Public Opinion and Political Parties in Advanced Industrial Democracies. $5^{\mathrm{a}}$ ed. Washington: CQ Press.

Dalton, R.; Farrell, D. \& McAllister, I., 2011. Political Parties and Democratic Linkage. Oxford: Oxford University Press.

Downs, A., 1957. An economic theory of democracy. New York: Harper \& Row Publishers.

Erikson, R.; Mackuen, M. \& Stimson, J., 2002. The Macropolity. New York: Cambridge University Press.

Freire, A. \& Belchior, A.M., 2013. Ideological Representation in Portugal: MPs'- electors' linkages in terms of Left-Right placement and substantive meaning. The Journal of Legislative Studies, 19(1), pp.1-21. DOI: $10.1080 / 13572334.2013 .736784$

Freire, A. \& Kivistik, K., 2013. Mapping and Explaining the Use of the Left-Right Divide. Brazilian Political Science Review, 7(3), pp.61-89. DOI: 10.1590/s1981-38212013000300003

Golder, M. \& Stramski, J., 2010. Ideological Congruence and Electoral Institutions. American Journal of Political Science, 54(1), pp.90-106. DOI: 10.1111/j.1540-5907.2009.00420.x

Hjorth, F.; Klemmensen, R.; Hobolt, S; Hansen, M.E. \& Kurrild-Klitgaard, P., 2015. Computers, Coders, and Voters: Comparing automated methods for estimating party positions. Research and Politics, 2(2), pp.1-9. DOI: $10.1177 / 2053168015580476$

Holmberg, S., 2011. Dynamic Representation from Above. In M. Rosema; B. Denters \& K. Aarts, eds. How Democracy Works: Political representation and policy congruence in modern societies. Amsterdam: Pallas Publications.

Huber, J. \& Powell, G.B. Jr., 1994. Congruence Between Citizens and Policy Makers in Two Visions of Liberal Democracy. World Politics, 46(3), pp.291-326. DOI: 10.2307/2950684

Klemmensen, R.; Hobolt, S.B. \& Hansen, M.E., 2007. Estimating Policy Positions Using Political Texts: An evaluation of the Wordscores approach. Electoral Studies, 26(4), pp.746-755. DOI: 10.1016/j.electstud.2007.07.006

Klingemann, H-D.; Volkens, A.; Bara, J.; Tanenbaum, E. \& McDonald, M., 2006. Mapping Policy Preferences II: Estimates for parties, electors and governments in Central and Eastern Europe, European Union and OECD: 1990-2003. New York: Oxford University Press.

Laver, M.; Benoit, K. \& Garry, J., 2003. Extracting Policy Positions from Political Texts Using Words as Data. American Political Science Review, 97(2), pp.311-331. DOI: 10.1017/s0003055403000698

Lowe, W., 2008. Understanding Wordscores. Political Analysis, 16(4), pp.356-371. DOI: 10.1093/pan/mpn004

Luna, J.P., 2014. Party System Institutionalization: Do we need a new concept? Studies in Comparative International Development, 49(4), pp.403-425. DOI: 10.1007/s12116-014-9171-1

Lupu N.; Selios L. \& Warner, Z., 2017. A New Measure of Congruence: The Earth Mover's Distance. Political Analysis, 25(1), pp.95-113. DOI: 10.1017/pan.2017.2

Madeira, R. \& Tarouco, G., 2011. Esquerda e direita no Brasil: uma análise conceitual. Revista Pós Ciências Sociais, 8(15), pp.171-185.

Przeworski, A.; Stokes, S. \& Manin, B., 1999. Introduction. In A. Przeworski; S. Stokes \& B. Manin, eds. Democracy, accountability, and representation. Cambridge: Cambridge University Press.

McDonald, M.; Mendes, S. \& Budge, I., 2004. What Are Elections For? Conferring the median mandate. British Journal of Political Science, 34(1), pp.1-26. DOI: 10.1017/s0007123403000322

Miguel, L.F., 2014. Democracia e representação: territórios em disputa. São Paulo: Ed. Unesp.

Miller, W. \& Stokes, D., 1963. Constituency Influence in Congress. American Political Science Review, 57(1), pp.45-56. DOI: $10.2307 / 1952717$

Monge, G., 1781. Mémoire sur la théorie des déblais et de remblais. Histoire de l'Académie Royale des Sciences de Paris, avec les Mémoires de Mathématique et de Physique pour la même année, 29, pp.666-704.

Oliveira, C. \& Turgeon, M., 2015. Ideologia e comportamento político no eleitorado brasileiro. Opinião Pública, 21, pp.574600. DOI: 10.1590/1807-01912015213574

Otero-Felipe, P. \& Rodríguez-Zepeda, J., 2010. Measuring Representation in Latin America: A study of ideological congruence between parties and voters. In 106th Annual Meeting of the American Political Science Association. Washington (DC).

Otero-Felipe, P. \& Rodríguez-Zepeda, J., 2015. El papel de la ideología en los partidos latinoamericanos. Revista Latinoamericana de Política Comparada, 9, pp.71-95.

Pederiva, J. \& Rennó, L., 2015. Responsividade democrática no Brasil de Lula e na Argentina dos Kirchner. Jundiaí: Paco Editorial. 
Pierce, R., 1999. Mass-Elite Issue Linkages and the Responsible Party Model of Representation. In W. Miller; R. Pierce; J. Thomassen; R. Herrera; S. Holmberg; P. Esaiasson \& B. Wessels, eds. Policy Representation in Western Democracies. Oxford: Oxford University Press.

Pitkin, H., 1967. The Concept of Representation. Berkeley: University of California Press.

Powell Jr., G.B., 2000. Elections as Instruments of Democracy: Majoritarian and proportional visions. New Haven: Yale University Press.

Powell Jr., G.B., 2009. The Ideological Congruence Controversy: The impact of alternative measures, data, and time periods on the effects of election rules. Comparative Political Studies, 42(12), pp.1475-1497. DOI: 10.1177/0010414009332147

Power, T. \& Zucco Jr., C., 2009. Estimating Ideology of Brazilian Legislative Parties 1990-2005: A research communication. Latin American Research Review, 44(1), pp.218-246. DOI: 10.1353/lar.0.0072

Przeworski, A.; Stokes, S. \& Manin, B., 1999. Democracy, Accountability, and Representation. Cambridge: Cambridge University Press.

Rennó, L.; Smith, A.; Layton, M. \& Pereira, F., 2011. Legitimidade e qualidade da democracia no Brasil. Uma visão da cidadania. São Paulo/Nashville: Intermeios/LAPOP.

Riker, W., 1982. Liberalism Against Populism. San Francisco: W.H. Freeman.

Rohrschneider, R. \& Whitefield, S., 2012. The Strain of Representation: How parties represent diverse voters in Western and Eastern Europe. Oxford: Oxford University Press.

Saiegh, S.M., 2015. Using Joint Scaling Methods to Study Ideology and Representation: Evidence from Latin America. Political Analysis, 23(4), pp.363-384. DOI: 10.1093/pan/mpv008

Selios, L., 2015. Receptividad democrática en América Latina: un análisis de congruencia ideológica em perspectiva diacrónica. In VIII Congreso Latinoamericano de Ciencia Política (ALACIP). Lima.

Singer, A., 2000. Esquerda e direita no eleitorado brasileiro. São Paulo: Edusp.

Slapin, J.B. \& Proksch, S-O., 2008. A Scaling Model for Estimating Time-Series Party Positions from Texts. American Journal of Political Science, 52(3), pp.705-722. DOI: 10.1111/j.1540-5907.2008.00338.x

Stimson, J., 1991. Public Opinion in America: Moods, cycles, and swings. Boulder: Westview.

Stimson, J.; Mackuen, M. \& Ericson, R., 1995. Dynamic Representation. American Political Science Review, 89, pp.543-65. DOI: $10.2307 / 2082973$

Tarouco, G., 2011. Brazilian Parties According to their Manifestos: Political identity and programmatic emphases. Brazilian Political Science Review, 5(1), pp.54-76.

Tarouco, G. \& Madeira, R., 2013. Partidos, programas e o debate sobre esquerda e direita no Brasil. Revista de Sociologia e Política, 21(45), pp.149-165.

Thomassen, J., 2012. The Blind Corner of Political Representation. Representation, 48(1), pp.13-27. DOI: $10.1080 / 00344893.2012 .653229$

Zechmeister, E. \& Corral, M., 2013. Individual and Contextual Constraints on Ideological Labels in Latin America. Comparative Political Studies, 46(6), pp.675-701. DOI: 10.1177/0010414012463880

Zucco Jr., C., 2011. Esquerda, direita e governo. A ideologia dos partidos políticos brasileiros. In T. Power \& C. Zucco JR., C., eds. O Congresso por ele mesmo. Autopercepções da classe política brasileira. Belo Horizonte: Ed. UFMG.

\section{Outras fontes}

Manifesto Project, 2017. Disponível em: https://manifesto-project.wzb.eu/. Acesso em: 16 mar. 2019.

The Methodological Debate in Studies of Policy Congruence: A review of the international literature

ABSTRACT Introduction: The bibliographic essay analyzes the international literature dedicated to empirically investigating the degree of congruence between the political preferences of voters and their representatives. The paper reviews the main topics of the methodological debate in this literature. Materials and Methods: We discuss the most influential articles in that debate, that is, the most cited and/or those whose methodological proposals were most used in later studies. The emphasis is in the comparison of the advantages and disadvantages assigned to the use of different sources and kinds of information for estimate those preferences and to the use of several indicators for calculate the degree of congruence between the preferences of the actors involved in the representational relationship. Results: At the end a balance is made, pointing out the methodological strategies considered most promising for this type of analysis. Discussion: It is expected that this review may encourage the development of this type of studies, still very incipient in Brazil and represent, for interested researchers, a shortcut to the understanding of the methodological aspects involved.

KEYWORDS: political representation; policy congruence; public opinion; representatives' policy preferences; methodology.

This is an Open Access article distributed under the terms of the Creative Commons Attribution Non-Commercial License which permits unrestricted non-commercial use, distribution, and reproduction in any medium provided the original work is properly cited. 


\section{Apêndice}

Figura A1. Medindo congruência vários-para-vários

Figura A1 - Medindo congruência vários-para-vários

País A
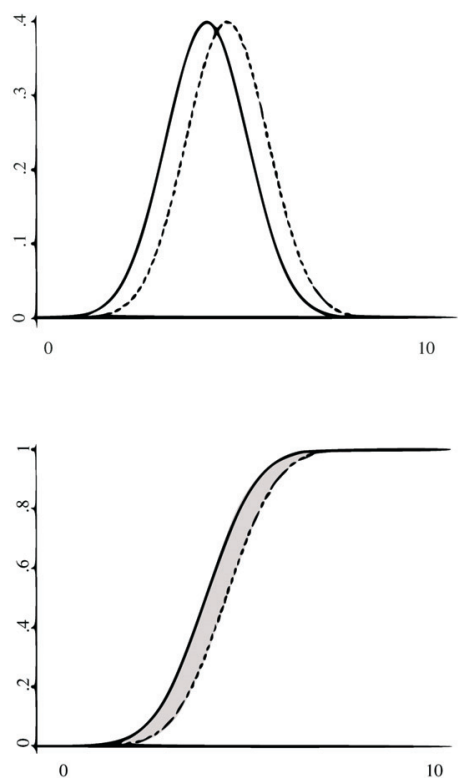

País B

Funções de Distribuição de Probabilidade

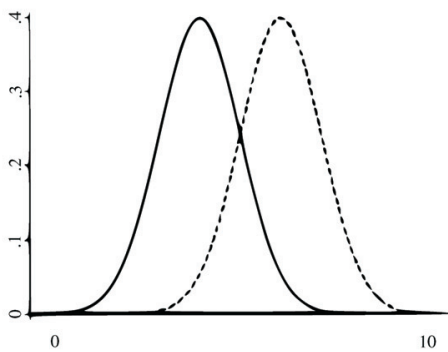

Funções de Distribuição Cumulativa

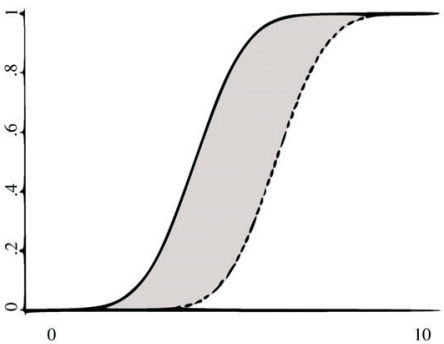

País C
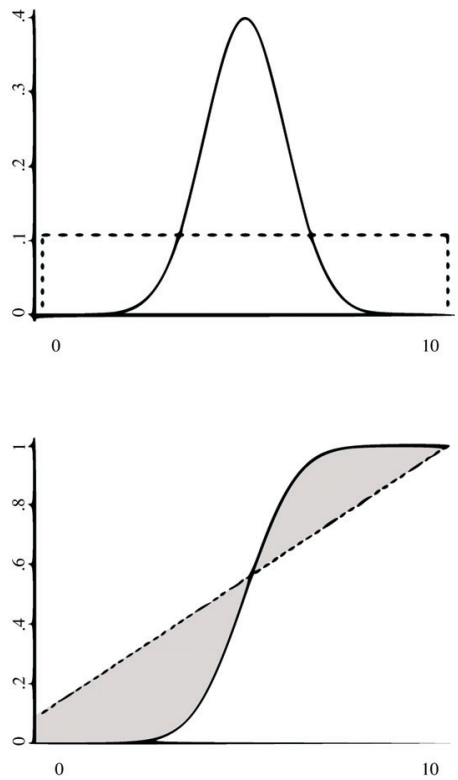

Cidadãos

Representantes

Fonte: O autor, a partir de Golder e Stramski (2010).

Nota: Distribuições de probabilidade e cumulativa em uma dimensão política que varia de zero a dez são mostradas em três países hipotéticos, A, B e C. O tamanho das áreas sombreadas indica o nível de congruência vários-para-vários em cada país; quanto maior a área sombreada, menor o nível de congruência entre cidadãos e representantes.

\section{Errata}

Página 6/28: último parágrafo, onde se lê "segundo Golder e Stramski (2010, p.204)", leia-se “segundo Golder e Stramski (2010, p.98)”.

Página 7/28: último parágrafo, onde se lê "Golder e Stramski (2010, p.205)", leia-se “Golder e Stramski (2010, p.99)”.

Página 9/28: primeiro parágrafo, onde se lê "(conforme análise de Alvarez e Franklin apud Golder e Stramski 2010, p.203)", leia-se "(conforme análise de Alvarez e Franklin apud Golder e Stramski 2010, p.93)”.

Página 14/28: quarto parágrafo, onde se lê "Golder \& Stramski 2010, p.188”, leia-se “Golder \& Stramski 2010, p.92”. Quarto parágrafo, onde se lê "(Golder \& Stramski 2010, pp.188-189)", leia-se "(Golder \& Stramski 2010, pp.92-93)".

Página 17/28: segundo parágrafo, onde se lê “"(não só com as preferências de um único representante, e.g., o governo), como nos casos anteriores, ou mesmo com as do representante mediano.”, leia-se "(não só com as preferências de um único representante, e.g., o governo ou o representante mediano).”. 